\title{
Monday-focused tailored rapid interactive mobile messaging for weight management 2 (MTRIMM2): results from a randomized controlled trial
}

\author{
Anna Y. Kharmats ${ }^{1,2}$, Chan Wang ${ }^{2}$, Laura Fuentes ${ }^{3} \wedge$, Lu Hu${ }^{2} \wedge$, Tina Kline ${ }^{3} \wedge$, Kevin Welding ${ }^{3} \wedge$, \\ Lawrence J. Cheskin ${ }^{4,5} \wedge$
}

${ }^{1}$ Bloomberg School of Public Health, Department of International Health, Johns Hopkins University, Baltimore, MD, USA; ${ }^{2}$ New York University Grossman School of Medicine, Department of Population Health, New York, NY, USA; ${ }^{3}$ Bloomberg School of Public Health, Department of Health, Behavior \& Society, Baltimore, MD, USA; ${ }^{4}$ George Mason University, College of Health and Human Services, Department of Nutrition and Food Studies, Fairfax, VA, USA; Johns Hopkins School of Medicine, Department of Medicine, Baltimore, MD, USA

Contributions: (I) Conception and design: LJ Cheskin, L Fuentes, T Kline, AY Kharmats; (II) Administrative Support: LJ Cheskin, L Fuentes; (III) Provision of study materials or patients: None; (IV) Collection and assembly of data: AY Kharmats, T Kline; (V) Data analysis and interpretation: AY Kharmats, C Wang; (VI) Manuscript writing: All authors; (V) Final approval of the version to be published: All authors.

Correspondence to: Anna Y. Kharmats. 180 Madison Ave., Seventh Floor, New York, NY 10016, USA. Email: anna.kharmats@nyulangone.org.

Background: Text-messaging interventions can reach many individuals across a range of socioeconomic groups, at a low cost. Few randomized controlled trials (RCTs) of text-messaging weight loss interventions have been conducted in United States.

Methods: From September of 2016 to September of 2018, we conducted a two-parallel group, superiority, RCT of a 16-week text-messaging, weight loss intervention in Baltimore, Maryland, in overweight and obese adults younger than 71 , who were able to receive text-messages. Our objective was to assess the effect of receiving the message content only (in printed documents distributed at baseline and week 8), versus receiving messages via short messaging service (SMS) on weight loss (primary outcome), body mass index, perceived exercise benefits and barriers, self-efficacy, and physical activity (PA). The random allocation sequence was equally balanced intervention groups by gender and age groups. Participants were randomized after the baseline assessment. Then, participants and most study staff were unblinded. Follow-up assessments were conducted at 8-, 16-, and 42-week post randomization. We performed intention-to-treat analysis using mixed linear regression models.

Results: Of the 155 adults randomized (printed messages =77, SMS =78), 87.1\% were women, 53.5\% were African Americans, and 93.5\% non-Hispanic. Participants who completed at least one follow-up assessment were included in regression analyses $(n=145$, printed messages $=74$, SMS $=71)$. Compared to baseline, at the 42-week assessment, the average percent weight loss was 1.23 for the SMS group $(\mathrm{P}=0.006)$ and 0.86 for the printed messages group $(\mathrm{P}=0.047)$. Both groups experienced small reductions in weight (printed messages: $-0.96 \mathrm{~kg}, \mathrm{P}=0.022$; SMS: $-1.19 \mathrm{~kg}, \mathrm{P}=0.006$ ), BMI (printed messages: $-0.32, \mathrm{P}=0.035$; SMS: $-0.52, \mathrm{P}=0.002$ ), and percent energy from fat consumption (printed messages: $-1.43, \mathrm{P}=0.021$; SMS: $-2.14, \mathrm{P} \leq 0.001$ ). No statistically significant between groups differences were detected for any of the study outcomes. SMS response rates were not statistically significantly associated with study outcomes. No adverse events were reported.

Conclusions: A semi-tailored SMS weight loss intervention among overweight and obese adults was not statistically superior in efficacy to paper-based messaging.

Trial Registration: ClinicalTrials.gov Identifier: NCT04506996.

Keywords: Obesity; mHealth; weight loss intervention; healthy diet; text messaging

\footnotetext{
^ ORCID: Anna Y. Kharmats, 0000-0002-9384-7344; Laura Fuentes, 0000-0002-5030-2301; Lu Hu, 0000-0003-1046-9614; Tina Kline, 0000-00020286-2187; Kevin Welding, 0000-0002-1833-6691; Lawrence J. Cheskin, 0000-0003-0262-1030.
} 
Received: 21 January 2021; Accepted: 12 June 2021; Published: 20 January 2022.

doi: 10.21037/mhealth-21-3

View this article at: https://dx.doi.org/10.21037/mhealth-21-3

\section{Introduction}

Approximately $40 \%$ of adults in the United States $(1,2)$ and approximately $32 \%$ of Baltimore City residents are obese (3). In 2018, the U.S. Preventative Services Task Force (USPSTF) recommended that adult patients who are obese be referred to behavioral interventions that target both diet and physical activity (PA), and suggests that patients should aim to achieve a $5 \%$ weight loss (4). For patients who are overweight but do not have cardiovascular disease risk factors, the decision to offer referrals should be individualized, but referral is recommended for overweight patients who have hypertension, dyslipidemia, pre-diabetes, or diabetes (4). Based on the results of a recent systematic literature review and meta-analysis, behavioral interventions have been found to be effective for weight loss and reduced the risk of developing type 2 diabetes mellitus (5).

Because $96 \%$ of Americans own a mobile phone, weight loss interventions delivered via mobile messaging, also known as short messaging service (SMS), offer an opportunity to reach many individuals across a range of socioeconomic groups at relatively low cost $(6,7)$. Unlike interventions delivered in-person, mobile health interventions reduce the burden on the participants to travel to appointments $(8,9)$. In addition, SMS interventions offer the opportunity for participants to get just-in-time messages during key decision-making moments.

However, there has been limited research on the effectiveness of SMS weight loss interventions. A 2020 systematic literature review and meta-analysis on weight loss and weight maintenance interventions in which SMS was the main intervention modality, identified only six randomized controlled trials (RCTs) conducted in the United States with adult participants (7). None of the RCTs followed the participants longitudinally after the completion of the interventions.

Furthermore, while there is growing evidence that dietary and health-related behaviors fluctuate across different days of the week, particularly between weekdays and weekends $(10,11)$, there has been limited research regarding the implications of these findings for behavioral interventions. For instance, studies of Google search volume on different days of the week, have demonstrated increased interest in healthy behaviors early in the week (12). In addition, there is initial evidence that a consistent pattern of compensatory caloric reduction early in the week versus weekend days are associated with successful weight loss outcomes $(13,14)$. A retrospective cohort study of 7,007 consistent users of a popular weight loss smart phone application identified fluctuating patterns of caloric consumption across the week. Greater weight loss occurred among users who recorded lower average consumption on Mondays relative to other days (10). However, to our knowledge no prior RCT has been conducted to determine whether a SMS-based weight loss intervention targeting key health behavior decisionmaking periods during the week results in improved weight loss compared to interventions using other intervention delivery methods.

To address these gaps, we conducted a text-messaging intervention study in a diverse sample of overweight or obese adults in Baltimore, Maryland. The objectives of the present study were to (I) evaluate the efficacy of a 16-week SMS intervention that targeted weekly periodicity in health behaviors using text messaging, and (II) assess whether changes in key study outcomes were sustained six months after participants completed the intervention. We hypothesized that at the completion of the intervention, participants receiving the SMS intervention would sustain greater weight loss than the control participants receiving the same messages bundled in a printed packet, and that these improvements would be sustained 6 months postintervention completion. We present the following article in accordance with the CONsolidated Standards Of Reporting Trials (CONSORT) reporting checklist (available at https:// dx.doi.org/10.21037/mhealth-21-3).

\section{Methods}

Monday-Focused Tailored Rapid Interactive Mobile Messaging intervention for Weight Management 2 (MTRIMM2) was a two-parallel group, superiority, RCT of a 16-week text-messaging weight loss intervention, in Baltimore, Maryland, conducted from September of 2016 until September of 2018 (ClinicalTrials.gov Identifier: NCT04506996). 


\section{Eligibility}

The eligibility criteria were: (I) age $\geq 18$ and $<71$, (II) BMI $>25$, (III) willingness to receive text messages and having a phone that was capable of receiving text-messages. English proficiency was not pre-specified as an inclusion criterion. However, all participants were proficient in English. There were no exclusion criteria.

\section{Recruitment}

Participants were recruited from the East Baltimore communities surrounding Johns Hopkins Hospital in Baltimore City, Maryland. In-person recruitment events took place at a Walgreens pharmacy, through the Brancati Center for the Advancement of Community Care, and in an indoor public food market near the medical campus. Additionally, flyers were distributed to faith-based and foodrelated community programs, the Johns Hopkins Weight Management Center, throughout medical and educational facilities, at clinics, and at housing complexes. Recruitment ended due to funding limitations. The study was conducted in accordance with the Declaration of Helsinki (as revised in 2013), and was approved by the Johns Hopkins Bloomberg School of Public Health's Institutional Review Board (IRB number: 00007115). All participants in the study provided written consent and received gift cards for participating.

\section{Intervention strategy}

The content of the MTRIMM2 intervention was informed by the formative research conducted for a prior successful text-messaging intervention with primarily African American participants in Baltimore, Maryland (15). The intervention was developed using concepts from the transtheoretical model, the health belief model, and self-regulation theory (16-19). A unique feature of this intervention was that each Monday served as an opportunity for participants to have a fresh start. Participants were encouraged to reach a new specific goal each week. The goals guided participants through certain processes of behavior change by: (I) by raising consciousness (by exposing participants to new ideas that support health behavior change) and providing cues to action, (II) counter conditioning (by encouraging participants to engage in simple and attainable substitutions of healthy behaviors for unhealthy behaviors), (III) stimulus control (removing cues that might result in unhealthy behaviors), and (IV) increasing participants' self-efficacy to avoid deviating from their goals in tempting situations (16). The remaining messages served as cues for participants to create plans to achieve their goals, provided tips for overcoming barriers participants experienced in reaching their goals, offered reminders for participants to self-monitor, and provided encouragement $(16,19)$.

\section{Educational intervention received by all participants}

After participants completed the baseline assessment, study staff reviewed educational materials with study participants regarding: (I) the benefits of increased $\mathrm{PA}$ and ideas for increasing PA (20), and (II) making healthier food choices, using an American Diabetes Association handout, which encouraged increasing consumption of fruits and nonstarchy vegetables, choosing whole grains instead of food made with refined grains, choosing lean sources of protein, choosing low-fat dairy and milk products, and limiting intake of sugary beverages and high-calorie snack foods and desserts (21).

After participants completed their week 8 study assessment, they were provided with additional educational materials regarding increasing PA, examples of aerobic exercise, strength training, and life-style activities that could help them be more active, and were walked through common barriers to engaging in PA as well as potential solutions. Finally, participants received tips about how to pick healthier food options at fast-food restaurants (22). See https://cdn.amegroups.cn/static/public/mhealth-21-3-1.pdf for a copy of the educational materials provided to study participants.

\section{SMS group}

The SMS group received at least seven text messages each week for 16 weeks. The messages centered around eight goal topics: (I) eating only when hungry, (II) increasing lifestyle-related PA and reducing sedentary behavior, (III) exercising more, (IV) eating less sugar and reducing calories from beverages, (V) eating a lower fat diet, (VI) eating a balanced diet, (VII) controlling portion sizes, and (VIII) making healthier food choices in social situations.

Depending on the day of the week, the text messaging topics varied (see Table 1 for the weekly schedule of messages topics, and https://cdn.amegroups.cn/static/ public/mhealth-21-3-2.pdf for the full list of messages participants received). For each of the eight goal topics, six goals were developed by the study team. The order that 
Table 1 The weekly schedule of messages topic and examples of messages sent

\begin{tabular}{|c|c|c|}
\hline Timing & Topic or purpose & Example of messages sent \\
\hline $\begin{array}{l}\text { Sunday } \\
\text { evening }^{\dagger \neq}\end{array}$ & Select goal topic for next week & $\begin{array}{l}\text { Example: "Which topics would you like to receive tips about next } \\
\text { week? Text "A" for low fat diet, "B" for eating in social situations, } \\
\text { "C" for being more physically active." }\end{array}$ \\
\hline $\begin{array}{l}\text { Monday } \\
\text { morning }\end{array}$ & Goal for the week & $\begin{array}{l}\text { Example: "When choosing snacks this week, opt for raw veggies, } \\
\text { nuts, fruit, whole grain crackers or low fat cheeses." }\end{array}$ \\
\hline $\begin{array}{l}\text { Monday } \\
\text { evening }\end{array}$ & $\begin{array}{l}\text { Question: were plans made to reach the week's } \\
\text { goal? }\end{array}$ & $\begin{array}{l}\text { Example: "Have you planned your meals and snacks for the week } \\
\text { yet? Planning can help you avoid fatty foods." }\end{array}$ \\
\hline $\begin{array}{l}\text { Wednesday } \\
\text { morning }^{\ddagger}\end{array}$ & $\begin{array}{l}\text { Reminder or a tip on how to reach the week's } \\
\text { goal }\end{array}$ & $\begin{array}{l}\text { "There are a lot of strategies for avoiding high-fat foods. If you } \\
\text { cannot find a low-fat version of your favorites, try something new!" }\end{array}$ \\
\hline $\begin{array}{l}\text { Wednesday } \\
\text { evening }\end{array}$ & Food carvings ${ }^{\S}$ & $\begin{array}{l}\text { "Remember, if you'd like an extra tip or are experiencing a craving, } \\
\text { just text back 'tip' to this number." }\end{array}$ \\
\hline Friday morning & $\begin{array}{l}\text { Congratulations for getting through the week and } \\
\text { reminder to keep perusing their goals during the } \\
\text { weekend }\end{array}$ & $\begin{array}{l}\text { "It's Friday! Congratulations on making it to the end of the week! } \\
\text { Remember your goals as you plan for the weekend!" }\end{array}$ \\
\hline Friday evening & Question about current weight & "Step on the scale. How many pounds do you weigh?" \\
\hline
\end{tabular}

these goal topics, goals, and default goals were chosen or sent to the study participants each week was predetermined using randomization to make sure that participants did not receive the same goals multiple times. For example, everyone who selected that they would like to receive a message regarding eating a lower fat diet on week one of the intervention, received the following goal "This week, check if the food you love has more than $10 \%$ of the saturated fat you need per day. Try to find lower fat versions by comparing nutrition labels". Everyone who selected that topic on week nine, received another goal.

Table 2 provided examples of goals messages (sent on Monday Mornings) and reminders and tip messages (sent on Wednesday Mornings). Due to an unknown error, during the first week of the text-messaging intervention, participants' weight was recorded as 100 pounds (which is lower than any participants' weight). Consequently, the next time participants answered how much they weighed (in response to weekly Friday evening text-messages), they were categorized as having gained weight even if they did not and received a response to not get discouraged about their progress. The subsequent responses were recorded correctly, and participants received the correct feedback.

We used Textit in as a text-messaging platform for designing the messaging architecture and housing the messaging content. We initially used Clickatell as an 
Table 2 Select examples of goals messages (Monday morning) and reminder and tip messages (Wednesday morning)

\begin{tabular}{|c|c|}
\hline Topic & Examples of messages \\
\hline Goal & $\begin{array}{l}\text { This week, try to drink beverages that do not have added sugar. Water is the best, and you can use } \\
\text { lemons, cucumbers, or watermelon to add flavor! }\end{array}$ \\
\hline Reminder/tip & $\begin{array}{l}\text { You probably have been doing great with your diet so far! Keep it up - consistency is key. Try to drink } \\
\text { beverages without sugar today! }\end{array}$ \\
\hline Goal & $\begin{array}{l}\text { This week, have } 1 \text { extra serving of fruits and veggies a day. Replace your midday snack with a fruit } \\
\text { or add an extra side of veggies to your dinner plate }\end{array}$ \\
\hline Reminder/tip & Good morning! Make sure to enjoy plenty of whole grains, fruits and vegetables today! \\
\hline \multicolumn{2}{|c|}{ Eating a low-fat diet } \\
\hline \multicolumn{2}{|c|}{ Controlling portion sizes } \\
\hline Goal & $\begin{array}{l}\text { This week, read labels to find out the serving size. Sometimes it is not obvious ( } 1 \text { bottle of soda } \\
\text { might have } 2 \text { servings!) }\end{array}$ \\
\hline Reminder/tip & $\begin{array}{l}\text { Eating in front of a TV can make us pay less attention to how much we consume. Try to avoid } \\
\text { overeating today by making sure the TV is off while you eat }\end{array}$ \\
\hline \multicolumn{2}{|c|}{ Eating only when Hungry } \\
\hline Goal & $\begin{array}{l}\text { This week, keep foods that tempt you out of your sight and in harder to reach places. Remember: } \\
\text { Out of sight, out of mind! }\end{array}$ \\
\hline Reminder/tip & $\begin{array}{l}\text { Even if you want to enjoy a meal out or order from a carryout, you can make good choices. Split a } \\
\text { meal with a friend, \& choose low-fat, low-calorie options }\end{array}$ \\
\hline \multicolumn{2}{|c|}{ Increasing lifestyle related physical activity \& reducing sedentary behavior } \\
\hline Goal & $\begin{array}{l}\text { Find time to squeeze activity into your schedule. Start by taking five-minute breaks during the day to } \\
\text { be physically active. Take a walk, tidy up, or stretch }\end{array}$ \\
\hline Reminder/tip & $\begin{array}{l}\text { It is another active day! Get up, do some stretches, touch your toes, walk around the house/office! } \\
\text { There are so many options! }\end{array}$ \\
\hline \multicolumn{2}{|l|}{ Exercising more } \\
\hline Goal & $\begin{array}{l}\text { This week, try to include both resistance \& aerobic exercise in your fitness routine! You can lift } \\
\text { weights, do wall-squats, and take a walk, bike, or dance! }\end{array}$ \\
\hline Reminder/tip & $\begin{array}{l}\text { Today, try changing up how hard you exercise! For example, you can go for a walk and then switch } \\
\text { to jogging every } 30 \text { seconds }\end{array}$ \\
\hline
\end{tabular}


aggregator (a company that sends the messages to study participants). However, in April of 2017, several participants reported that they stopped receiving text-messages for approximately two weeks. We learned that Clickatell was reporting false positive text-message delivery statuses, and this may have affected up to 25 participants who were actively receiving the intervention. In response, we switched to a different aggregator, Twilio. To deliver the missed content, we extended the intervention period for the potentially affected text-messaging participants for up to two weeks, unless participants notified us that they did not experience an interruption.

\section{Printed messages group}

Participants in the printed messages group received a printed copy of the same messages that the SMS group received (see https://cdn.amegroups.cn/static/public/ mhealth-21-3-2.pdf). However, the first eight weeks' worth of messages and craving tips were given after the baseline assessment, and the rest were given after the first follow-up assessment ( $\sim 8$ weeks post randomization). The messages for each week were clearly laid out and labeled. Participants were given spaces to record their answers (i.e., which goal they were selecting for each week). The study staff reviewed the first week's messages together with the study participants to get participants comfortable with the format of the printed messages.

\section{Randomization}

A statistician configured the REDCap $(23,24)$ randomization module (a Web-based survey program) so that the allocation sequence generated in Excel using the RAND function equally balanced treatment groups by gender and age groups (18-21, 22-40, 41-70 years). The allocation sequence using a block size of four, was concealed from all other study staff. Participants were randomized after completing the baseline assessment in REDCap. The study's principal investigator, but not the study staff, was blinded to the randomization results.

\section{Data collection}

Data for the MTRIMM2 study was collected at four times: (I) baseline, (II) eight weeks after participants were randomized (mid-way through the intervention), (III) at the completion of the intervention 16 weeks post- randomization, and (IV) 42 weeks after randomization (6 months after completion of the intervention). Study surveys were administered using REDCap. Participants had the choice of completing the study questionnaires on their own, using their own computers, prior to the inperson study visit or using a tablet or paper form during a study visit. Participants also had the option to have the data collectors read each question and record their answers.

\section{Outcome assessment}

The primary study outcomes were percent weight change from baseline at each study visit. The secondary outcomes were the absolute change in BMI $\left(\mathrm{kg} / \mathrm{m}^{2}\right)$, fruit and vegetable intake, fat intake, PA, self-efficacy, and perceived benefits of and barriers to exercise.

\section{Weight}

Participants had a choice of two different locations to have their height and weight measured by trained study staff. Participants were asked to complete their followup appointments at the same location as their baseline appointment, to avoid using different scales. At one location, weight was measured using a physician beam scale, which was calibrated each day using standard weights. An electronic scale was used at the second location. Participants were asked to take off their shoes, heavy clothing, and objects from their clothing and pockets that could affect their measurements.

\section{Height}

Height was measured at least twice at each study visit, with participants' shoes off, using stadiometer (Seca 213 Portable Measuring Rod, Chino, CA). Data collectors were trained to ensure that participants' head positions produced parallel and level Frankfort Horizontal planes. If the two height measurements differed by $>0.25$ inches, a third measurement was taken, and all values were averaged. Height was then averaged across all study visits.

\section{Daily average fruit and vegetable servings consumed}

Fruit and vegetable intake was measured using National Cancer Institute's (NCI) 19-item All-Day Fruit and Vegetable Screener, which was developed based on results from the Eating at America's Table study (25-27). The questionnaire assessed consumption frequency and portion sizes. Participants were asked about fruits and vegetables eaten alone or in combination with other foods, as well 
foods and beverages such as fruit juices, lettuce/salad, potatoes, dried beans, vegetable soups, and tomato sauces. Study participants were shown measuring cups to help them better estimate portion sizes. The total daily average fruit and vegetable servings consumed was calculated using NCI's 2001 scoring protocol and procedures for handling missing data (28).

\section{Percent energy from fat}

Percent energy from fat intake was assessed using the NCI's 16-item Percent Energy from Fat Screener (29-31). The screener assessed the consumption frequency of items such as skim milk, margarine, butter, mayonnaise, oil, salad dressings, sausages, beef, cheese, cereal, and fruits. The eight answer choices ranged from "never [in the past year]" to " 2 or more times per day." In addition, participants were asked how often they used reduced-fat margarine when they prepared food. Percent energy from fat intake was calculated using to the NCI's 2004 scoring protocol (32).

\section{PA}

PA performed for at least 10 minutes at a time in the week prior to completing study surveys was assessed using the long version of the International Physical Activity Questionnaire (IPAQ) (33). The questionnaire focused on four domains of PA: (I) performed at work or during volunteer activities, (II) transportation-related (such as walking to do errands), (III) performed during housework and caring for family, and (IV) recreational, sport, and leisure-time PA (33). Participants were asked about the number of days, hours, and minutes they performed each activity.

This data was used to calculate the total metabolic equivalent of tasks (MET)-minutes per week, and the MET values for walking, moderate, and vigorous $\mathrm{PA}$ based on the IPAQ 2005 data processing and analysis guidelines, but with two modifications (34). First, instead of truncating the hours of time spent walking, and engaging in moderate and vigorous PA to 21 hours per week for each category, we first identified the MET values that corresponded to the highest intensity PA within each category (i.e., 3.3 MET for walking, 5.5 MET in the moderate PA, 8 MET for vigorous $\mathrm{PA})$. Then, we calculated the total MET-minutes of engaging in those activities for 21 hours/week, and truncated data within each category based on those MET values (4,158 MET-minutes/week for walking, 7,560 METminutes/week for moderate PA, and 10,080 MET-minutes/ week for vigorous $\mathrm{PA}$ ).

Second, due to a lack of instructions on how to handle truncation of data for individual variables (i.e., moderate PA while doing yard work), we were not able to calculate valid totals for each of the four domains of PA (transportation $\mathrm{PA}, \mathrm{PA}$ at work, leisure time $\mathrm{PA}$, and domestic $\mathrm{PA}$ ).

\section{Self-efficacy to lose weight}

Self-efficacy to lose weight was assessed using the 20item Weight Efficacy Lifestyle Questionnaire (WEL) (35). The items assessed ability to resist eating in 20 different situations, classified in five domains: (I) when experiencing negative emotions, (II) when a variety of food is available, (III) when experiencing social pressure, (IV) when experiencing physical discomfort, and $(V)$ when engaging in "positive" activities such as reading, watching television, and getting ready to going to bed. A 10-point response scale was used, with answers ranging from zero to 9. Higher scores represent greater confidence in being able to avoid eating.

\section{Benefits of and barriers to exercise}

The 43-item Exercise Benefits/Barriers Scale (EBBS) was used to assess the perceived benefits of exercise and barriers to exercise experienced by study participants (36). Participants were asked how much they agreed or disagreed with statements such as and "I will live longer if I exercise" (exercise benefit) and "exercise takes too much time from family relationships" (exercise barrier). For the Exercise Benefit Scale, a four-point response scale was used: "strongly disagree" $=1$, "disagree" $=2$, "agree" $=3$, and "strongly agree" $=4$, with higher score representing greater perceived benefit of exercising. Answers for the Exercise Barrier Scale were reverse scored, and higher scores corresponded to greater perceived barriers to engaging in exercise.

\section{Engagement with the interventions}

To assess participants' engagement with the intervention, participants rated on a 5-point Likert scale, ranging from strongly agreed to strongly disagree, whether they read every message that was either sent via SMS or provided to them in a printed format. In addition, for participants in the SMS group, the response rates to text-messages that asked questions were tracked. However, participants were informed that responding to the text messages was optional.

\section{Statistical analysis}

Descriptive statistical analyses were conducted using STATA version 15.1 software (StataCorps LLC, College Station, 
TX, USA). Using Statistical Analysis Software version 9.4 (SAS Institute Inc., Cary, NC, USA), we conducted intention-to-treat analysis using piecewise linear mixed regression models, with random intercepts and slopes, in order to use all available data from participants who completed at least one follow-up assessment. This reduces the chance for a Type I error (incorrectly rejecting the null hypothesis) compared to repeated measures ANOVA models. Fixed effects were included for the study arm (SMS $v s$. printed messaging), two time periods, and interactions of study arm and time period. A random effect was included for the participants. Depending on the trajectory of the study outcomes over time, either $0-8$ and $8-42$ weeks, or $0-16$ and 16-42 weeks two time periods were employed in the models. To assess the change over the whole study period (from 0 to 42 weeks), we also ran linear mixed regressions to estimate the overall trend in study outcomes from 0 to 42 weeks. Results were considered statistically significant if $\mathrm{P}$ value were $\leq 0.05$.

\section{Sample size calculations}

Sample size calculations were based on published data from a similar study (15). We expected an effect size of 0.946 , with $95 \%$ confidence interval of 0.359 to 1.533 . The SMS group was expected to experience a weight loss of $3.7 \mathrm{~kg}$ $(\mathrm{SD}=4.28 \mathrm{~kg})$, and the control group a weight loss of $0.2 \mathrm{~kg}$ $(\mathrm{SD}=2.64 \mathrm{~kg})$. Twenty percent participant dropout was expected. Using a two-sided $t$-test of mean differences, to achieve a power of $80 \%$, a sample size of 48 participants in total was needed (95\% CI: 20-308). Our recruitment goal was 200 participants.

\section{Results}

\section{Study participants}

Of the 165 people who completed study screening, 156 met the inclusion criteria, and 155 enrolled and were randomized. Seventy-eight participants were randomized to receive SMS messages (SMS intervention group), and 77 to receive printed messages (printed messages group). However, two of the participants who were randomized to receive printed messages, received the SMS intervention in error. Nevertheless, we operated under the intention-to-treat model. After randomization, 146 participants completed the 8 -week follow-up assessment (94.2\%), 136 completed the 16-week follow-up (87.7\%), and 125 completed the 42 -week follow-up assessment (80.6\%). See Figure 1 for more details. Participants who completed at least one follow-up assessment were included in regression analyses $(n=146$, printed messages group $=74$, SMS group $=72$ )

Of the participants who completed the baseline assessment, $87.1 \%$ were women, $53.5 \%$ self-identified as African American or Black, 33.5\% as Caucasian or White, and $93.5 \%$ as non-Hispanic or Latinx. Participants' ages ranged from 21-68, with the average age of $44.6(\mathrm{SD}=13.4$, median $=46.1)$. Most participants were employed $(78.7 \%)$ and had diverse levels of educational attainment $(5.8 \%$ less than high school, $24.5 \%$ high school, $7.7 \%$ associates, trade, or vocational school, $31.6 \%$ Bachelor's degree, and $22.6 \%$ Master's degree, $7.1 \%$ professional or doctoral degrees, $0.6 \%$ not reported).

There were no statistically significant differences in baseline sociodemographic characteristics between the intervention and control groups. See Table 3 for details. There were also no statistically significant differences at baseline in the study outcomes between the SMS and the printed messages groups. See Table 4 for details.

\section{Engagement with the intervention}

In response to a statement "I read every M-TRIMM2 motivational message" of the 65 participants in the SMS group who answered, $67.7 \%$ strongly agreed and $16.9 \%$ agreed. In contrast, of the 67 participants in the printed messages group who answered, $22.4 \%$ strongly agreed and $28.4 \%$ agreed. This difference was statistically significant based on the Kruskal-Wallis rank test $(\mathrm{P}<0.001)$, and indicated that SMS group reported reading more of the messages they received than the printed messages group.

Most participants in the SMS group responded to messages asking them to select goals for the week (mean $=63.3 \%, \mathrm{SD}=27.3 \%, 80.5 \%$ at week $1,51 \%$ at week 16 ), and whether they made plans to reach their goals (mean $=57.6 \%, \mathrm{SD}=26.0 \%, 76.6 \%$ at week $1,46.8 \%$ at week 16 ). Fewer participants requested tips for dealing with cravings or reported their weight $(55.8 \%$ at week $2,39.0 \%$ at week 16$)$. See Table 5 for details. The changes in the weekly response rates are shown in Figure S1.

\section{Study outcomes}

Based on results of piecewise mixed linear regression models, at the 42 -week assessment, on average, both the printed messages group and SMS group experienced small 


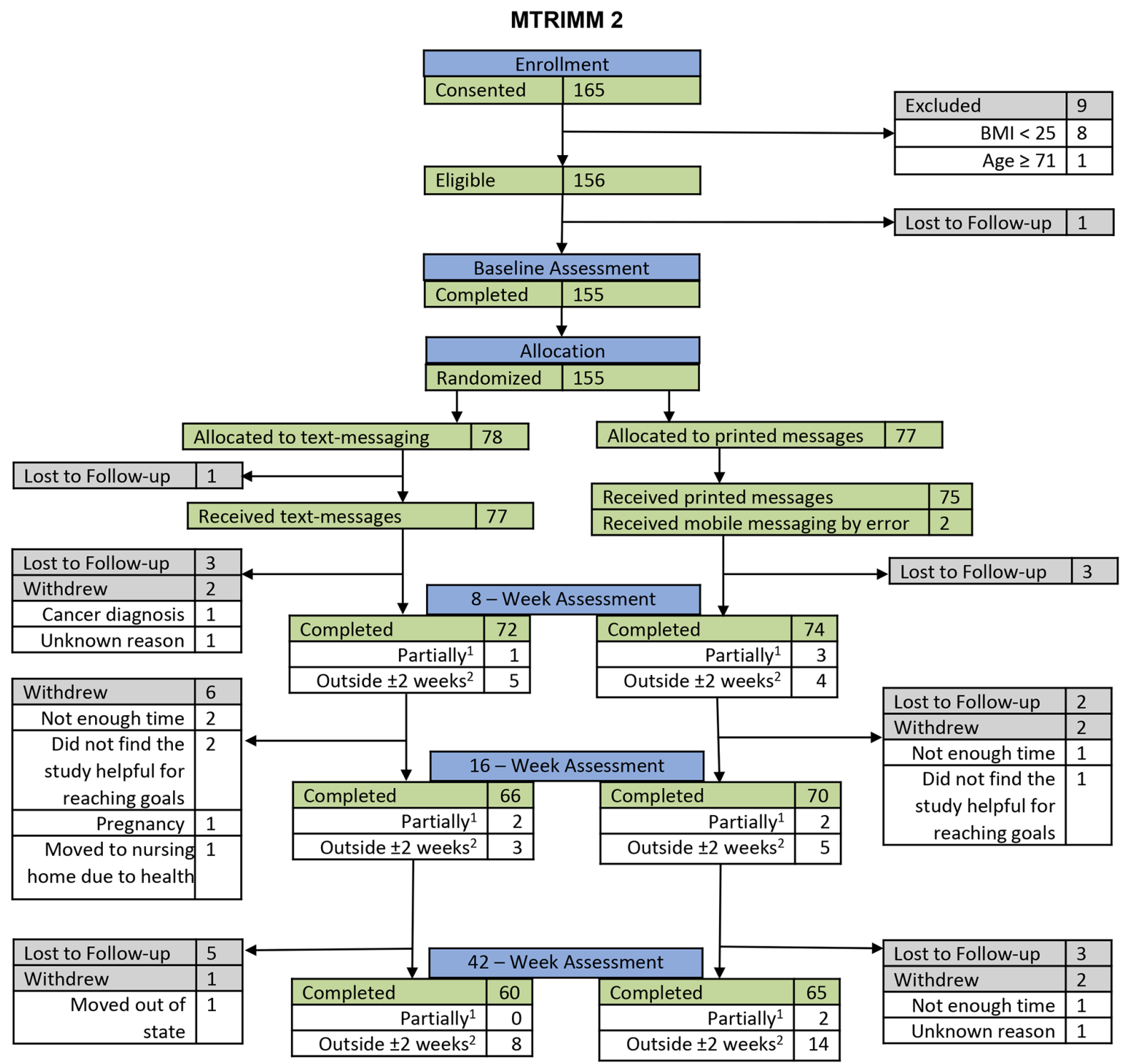

Figure 1 CONSORT diagram. ${ }^{1}$, of the participants who were counted as having completed study assessments, some only partially completed the assessments. ${ }^{2}$, number of participants who completed the assessments either earlier than two weeks before they were due for the assessment, or more than two weeks past the due date.

reductions in weight, BMI, and percent energy from fat consumption compared to baseline. The average percent weight loss from baseline, was 1.23 for the SMS group (95\% CI: 0.36 to $2.09 \mathrm{P}=0.006$ ) and 0.86 for the printed messages group ( $95 \% \mathrm{CI}: 0.01$ to $1.70, \mathrm{P}=0.047$ ) at the 42-week assessment (Figure 2). The corresponding weight loss (kg) for the SMS group was 1.19 (95\% CI: 0.35 to 2.03, $\mathrm{P}=0.006)$, and $0.96 \mathrm{~kg}$ for printed messages group (95\% CI: 0.14 to $1.78, \mathrm{P}=0.022$ ) (Figure S2). Similarly, compared to baseline, at 42 -week the average BMI decreased by 0.52 for the SMS group (95\% CI: 0.20 to $0.85, \mathrm{P}=0.002)$, and by 0.32 for the printed messages group (95\% CI: 0.02 to $0.65, \mathrm{P}=0.035$ ) (Figure 3). The percentage energy from fat consumption decreased by 2.14 (95\% CI: 0.89 to 3.39, $\mathrm{P}<0.001)$ for the SMS group and by 1.43 for the printed messages group (95\% CI: 0.22 to $2.63, \mathrm{P}=0.021$ ) (Figure 4).

No statistically significant differences were detected between the SMS group and the printed messages 
Table 3 Participant sociodemographic characteristics and BMI at baseline

\begin{tabular}{|c|c|c|c|c|c|c|c|c|}
\hline \multirow{2}{*}{ Participant characteristics } & \multicolumn{2}{|c|}{ Total $(n=155)$} & \multicolumn{4}{|c|}{ Treatment group according to randomized assignment } & \multirow{2}{*}{$\mathrm{Chi}^{2}$} & \multirow{2}{*}{$\mathrm{P}$} \\
\hline & $\mathrm{n}$ & $\%$ & $\mathrm{n}$ & $\%$ & $\mathrm{n}$ & $\%$ & & \\
\hline Age & & & & & & & 5.95 & 0.20 \\
\hline $18-29$ & 28 & 18.10 & 9 & 11.70 & 19 & 24.40 & & \\
\hline $50-59$ & 41 & 26.50 & 21 & 27.30 & 20 & 25.60 & & \\
\hline $60-70$ & 23 & 14.80 & 10 & 13.00 & 13 & 16.70 & & \\
\hline Gender & & & & & & & 0.00 & 0.98 \\
\hline High school/GED & 38 & 24.50 & 20 & 26.00 & 18 & 23.10 & & \\
\hline Associates/trade/vocational & 12 & 7.70 & 5 & 6.50 & 7 & 9.00 & & \\
\hline Bachelor's degree & 49 & 31.60 & 24 & 31.20 & 25 & 32.10 & & \\
\hline Master's degree & 35 & 22.60 & 15 & 19.50 & 20 & 25.60 & & \\
\hline Professional or doctoral & 11 & 7.10 & 7 & 9.10 & 4 & 5.10 & & \\
\hline Not reported & 1 & 0.60 & 1 & 1.30 & 0 & 0.00 & & \\
\hline Employment & & & & & & & 0.40 & 0.53 \\
\hline Employed & 122 & 78.70 & 59 & 76.60 & 63 & 80.80 & & \\
\hline Asian & 10 & 6.50 & 3 & 3.90 & 7 & 9.00 & & \\
\hline Other & 9 & 5.80 & 6 & 7.80 & 3 & 3.80 & & \\
\hline Not reported & 1 & 0.60 & 1 & 1.30 & 0 & 0.00 & & \\
\hline Ethnicity & & & & & & & 0.00 & 0.99 \\
\hline Hispanic & 6 & 3.90 & 3 & 3.90 & 3 & 3.80 & & \\
\hline Non-Hispanic & 145 & 93.50 & 73 & 94.80 & 72 & 92.30 & & \\
\hline Not reported & 4 & 2.60 & 1 & 1.30 & 3 & 3.80 & & \\
\hline Baseline BMI category & & & & & & & 2.76 & 0.43 \\
\hline Overweight $(30>\mathrm{BMI} \geq 25)$ & 35 & 22.60 & 16 & 20.80 & 19 & 24.40 & & \\
\hline Class I obesity $(35>$ BMI $\geq 30)$ & 49 & 31.60 & 21 & 27.30 & 28 & 35.90 & & \\
\hline Class II obesity (40> BMI $\geq 35)$ & 35 & 22.60 & 21 & 27.30 & 14 & 17.90 & & \\
\hline Class III obesity (BMI $\geq 40)$ & 36 & 23.20 & 19 & 24.70 & 17 & 21.80 & & \\
\hline
\end{tabular}

SMS, short messaging service; SNAP, Supplemental Nutritional Assistance Program. 
Table 4 Descriptive statistics for MTRIMM2 outcome variables by intervention group

\begin{tabular}{|c|c|c|c|c|c|c|}
\hline Outcomes & \multicolumn{2}{|c|}{ Printed messages group } & \multicolumn{2}{|c|}{ SMS group } & \multicolumn{2}{|c|}{ Differences at baseline } \\
\hline \multicolumn{7}{|l|}{ Weight (kg) } \\
\hline Baseline & 99.4 & 21.7 & 94 & 19.2 & 1.6 & 0.121 \\
\hline 8 weeks visit & 98.7 & 22 & 94 & 19.8 & & \\
\hline 42 weeks visit & 98.1 & 23 & 92.5 & 19.7 & & \\
\hline \multicolumn{7}{|l|}{ BMI } \\
\hline Baseline & 36.6 & 7.7 & 34.4 & 6.3 & 1.9 & 0.061 \\
\hline 8 weeks visit & 36.3 & 7.7 & 34.4 & 6.5 & & \\
\hline \multicolumn{7}{|c|}{ Exercise barriers total score } \\
\hline Baseline & 29.6 & 6.4 & 29.2 & 7.6 & 0.4 & 0.707 \\
\hline 8 weeks visit & 30.3 & 6.3 & 29.1 & 6.6 & & \\
\hline 16 weeks visit & 30.3 & 6.5 & 28.8 & 7.1 & & \\
\hline 42 weeks visit & 30.4 & 6.8 & 29.3 & 8 & & \\
\hline \multicolumn{7}{|c|}{ Exercise benefit score } \\
\hline Baseline & 93.2 & 12.6 & 93.8 & 11.3 & -0.3 & 0.753 \\
\hline 8 weeks visit & 91.1 & 13.1 & 91.8 & 11.4 & & \\
\hline 16 weeks visit & 3.5 & 3.5 & 3.4 & 4.4 & & \\
\hline 42 weeks visit & 2.9 & 2.9 & 3.2 & 3.5 & & \\
\hline \multicolumn{7}{|c|}{ Percent energy from fat } \\
\hline Baseline & 34.6 & 6.5 & 34.3 & 7.4 & 0.3 & 0.769 \\
\hline 8 weeks visit & 33.3 & 4.1 & 32.5 & 4.6 & & \\
\hline 16 weeks visit & 33.1 & 6.7 & 32.7 & 5.2 & & \\
\hline 42 weeks visit & 33.5 & 8 & 32.5 & 4.9 & & \\
\hline \multicolumn{7}{|c|}{ Weight efficacy lifestyle questionnaire score } \\
\hline Baseline & 92.4 & 44.7 & 100.5 & 34.9 & -1.2 & 0.226 \\
\hline 8 weeks visit & 95.9 & 41.8 & 97.5 & 37.8 & & \\
\hline 16 weeks visit & 101.7 & 41.7 & 101.6 & 37.7 & & \\
\hline 42 weeks visit & 101.4 & 46.6 & 108.8 & 36.7 & & \\
\hline
\end{tabular}

Table 4 (continued)

(c) mHealth. All rights reserved. 
Table 4 (continued)

\begin{tabular}{|c|c|c|c|c|c|c|}
\hline Outcomes & \multicolumn{2}{|c|}{ Printed messages group } & \multicolumn{2}{|c|}{ SMS group } & \multicolumn{2}{|c|}{ Differences at baseline } \\
\hline \multicolumn{7}{|c|}{ Physical activity－total MET mins/week } \\
\hline Baseline & $4,276.2$ & $4,020.7$ & $4,797.6$ & $4,337.2$ & -0.7 & 0.461 \\
\hline 8 weeks visit & $4,692.4$ & $4,984.8$ & $4,527.2$ & $4,206.9$ & & \\
\hline 42 weeks visit & $4,639.2$ & $4,643.4$ & $5,049.2$ & $4,945.7$ & & \\
\hline \multicolumn{7}{|c|}{ Physical activity - walking MET mins/week } \\
\hline Baseline & $1,651.8$ & $1,491.9$ & 1,586 & $1,451.7$ & 0.3 & 0.791 \\
\hline 8 weeks visit & $1,593.4$ & $1,391.2$ & $1,557.7$ & 1,433 & & \\
\hline \multicolumn{7}{|c|}{ Moderate physical activity MET mins/week } \\
\hline Baseline & $1,732.4$ & $1,933.9$ & $2,204.6$ & $2,360.1$ & -1.3 & 0.197 \\
\hline 8 weeks visit & $1,767.3$ & 2,001 & $1,870.6$ & $2,007.2$ & & \\
\hline 16 weeks visit & $2,086.4$ & $2,414.3$ & $1,882.2$ & $2,010.2$ & & \\
\hline 42 weeks visit & $1,957.4$ & $2,131.2$ & 2,362 & $2,566.6$ & & \\
\hline \multicolumn{7}{|c|}{ Vigorous physical activity MET mins/week } \\
\hline Baseline & 891.9 & $1,865.3$ & 1,007 & $1,636.4$ & -0.4 & 0.697 \\
\hline 8 weeks visit & $1,331.7$ & $2,511.1$ & $1,098.9$ & $2,160.6$ & & \\
\hline
\end{tabular}

Data was only used for participants who completed at least one follow-up assessment in addition to the baseline assessment. No statistically significant differences between intervention groups were observed at baseline. In a sensitivity analysis, using data from all participants regardless of whether they completed follow-up assessments, there also were no statistical differences in baseline values between the SMS and printed messages group. SMS, short messaging service.

group over time for any of the study outcomes. See Table 6, Figures 2-4, and Figures S3-S10 for results of piecewise mixed linear regression models. Results of regressions examining the overall trends over the 42-week study period, without the piecewise component, are presented in Table S1. For the SMS group, response rates to text-messages were not statistically significantly associated with study outcomes (Table S2). No adverse events were reported by the study participants.

\section{Sensitivity analysis}

We conducted an as treated analysis (the two participants who received text messages by mistake as being in the SMS group) to examine whether regression results differed for the intention to treat analysis (the two participants were treated as being in the printed messages group to which they were randomized). Results remained qualitatively the same, see Table S3.

\section{Discussion}

The published literature indicates evidence of weekly fluctuating patterns of health behaviors and caloric consumption (10-14). This study sought to develop and evaluate an SMS-based weight loss periodic messaging 
Table 5 Percentage of text-messages that participants in the mobile messaging group responded to over the 16-week intervention out of the messages that asked questions $(\mathrm{n}=78)$

\begin{tabular}{lcc}
\hline Day of the week and topic & Mean \% (SD) & Median \% (IQR) \\
\hline Sunday: selecting goal (out of 3 options) & $63.3(27.3)$ & $68.8(50.0-81.2)$ \\
Monday: responded that a plan was made to reach the weekly goal & $57.6(26.0)$ & $62.5(37.5-81.25)$ \\
Wednesday: request for tip on dealing with cravings & $38.8(35.0)$ & $31.3(6.3-62.5)$ \\
Friday: reported weight (excluding first week) ${ }^{\dagger}$ & $44.9(32.7)$ & $40(13.3-66.7)$ \\
All messages & $51.2(24.1)$ & $54.0(33.3-68.6)$
\end{tabular}

${ }^{\dagger}$, accurate data on responses to the weight question during the first week of the intervention was not available due to an error of unknown origin. IQR, interquartile range.

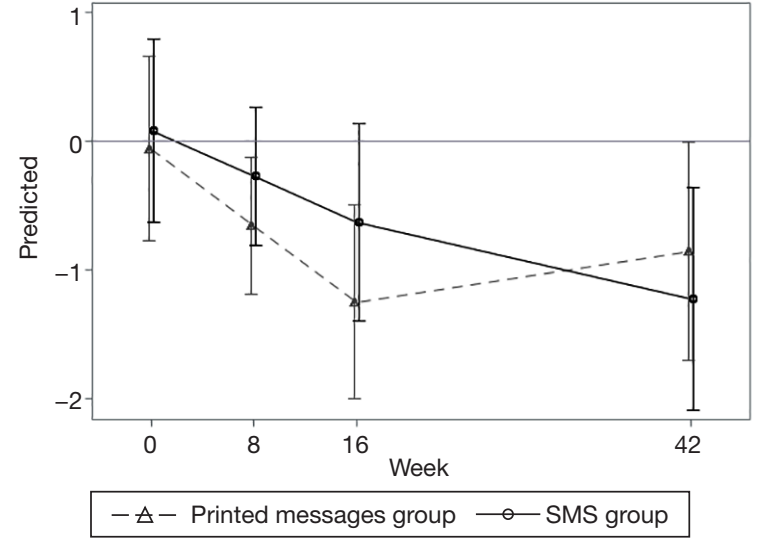

Figure 2 Results of piecewise linear mixed model: average change in percent weight loss from baseline in the SMS and printed messaging groups with $95 \%$ confidence intervals. Percent weight loss was calculated by subtracting baseline weight from weight at 8,16 , and 42 weeks and multiplying results by 100 . SMS, short messaging service.

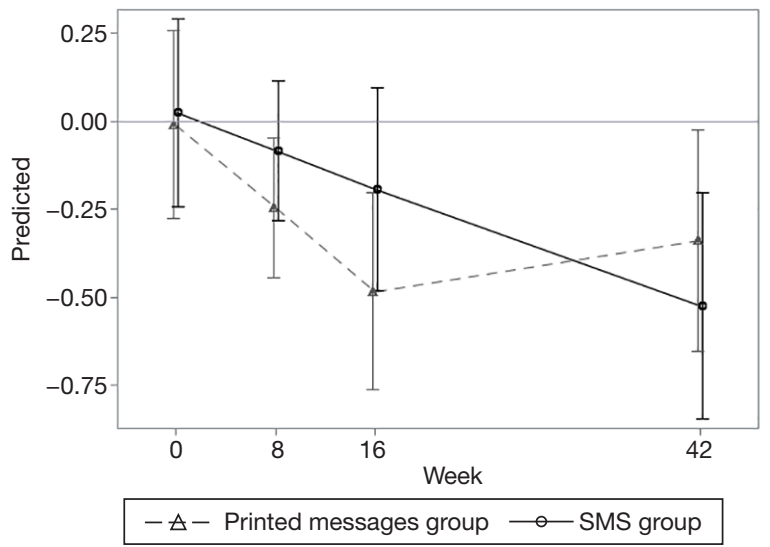

Figure 3 Results of piecewise linear mixed model: average change in BMI from baseline in the SMS and printed messaging groups with $95 \%$ confidence intervals. SMS, short messaging service; BMI, body mass index.

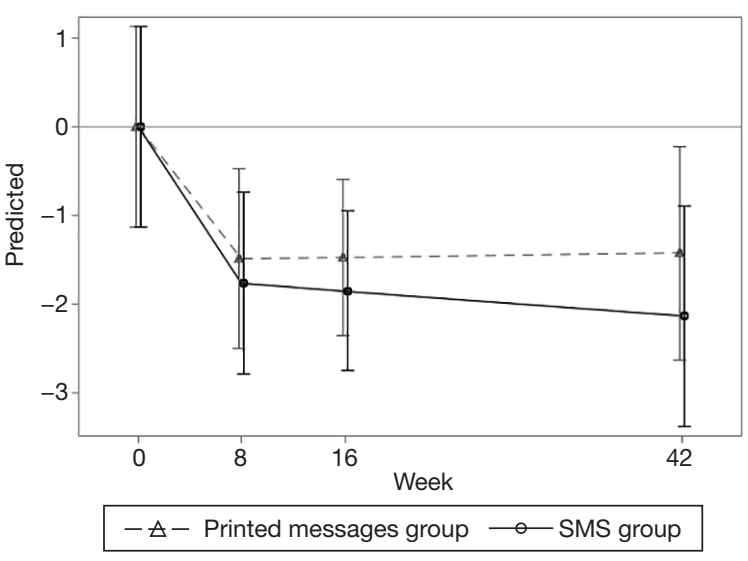

Figure 4 Results of piecewise linear mixed model: average differences in percent of energy from fat from baseline in the SMS and printed messaging groups with $95 \%$ confidence intervals. SMS, short messaging service.

intervention that that prompts participants to start fresh each week, embark on a new goal each Monday, and committee to engaging in healthy behaviors even on the weekends. Weight loss interventions delivered via SMS provide an opportunity to reach a large number of participants at a relatively low cost and can also allow participants to receive timely feedback without the inconvenience of in-person appointments. However, the results of our randomized control trial of the MTRIMM2 16-week weight loss intervention did not identify statistically significant differences between the SMS and printed messages groups for any of the study outcomes [percent weight loss, weight loss $(\mathrm{kg})$ ], BMI, perceived exercise benefits and barriers, scores on the Weight Efficacy Lifestyle questionnaire, and PA measured as METs/week [total PA, walking PA, moderate $\mathrm{PA}$, vigorous $\mathrm{PA}$ )] at the 


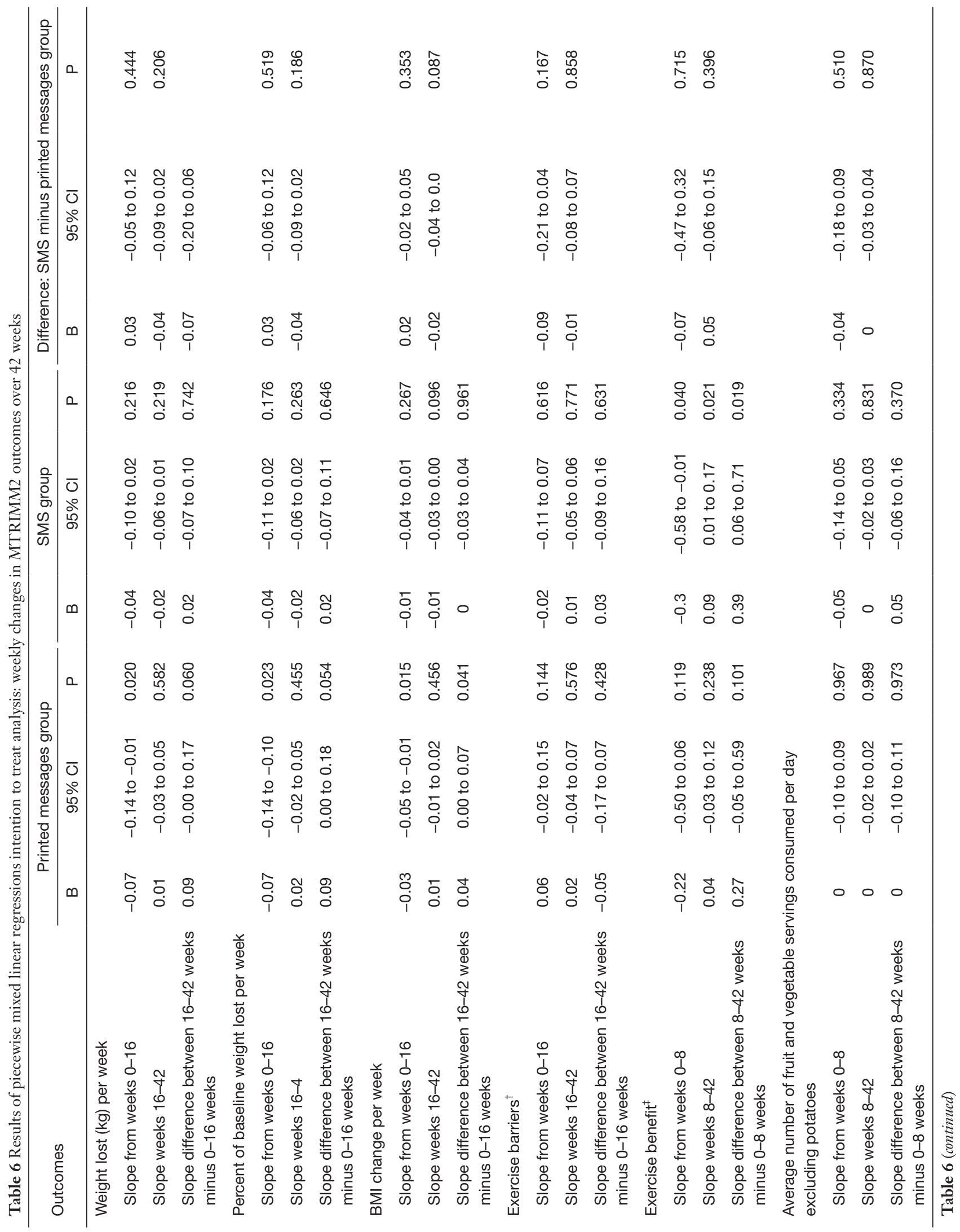




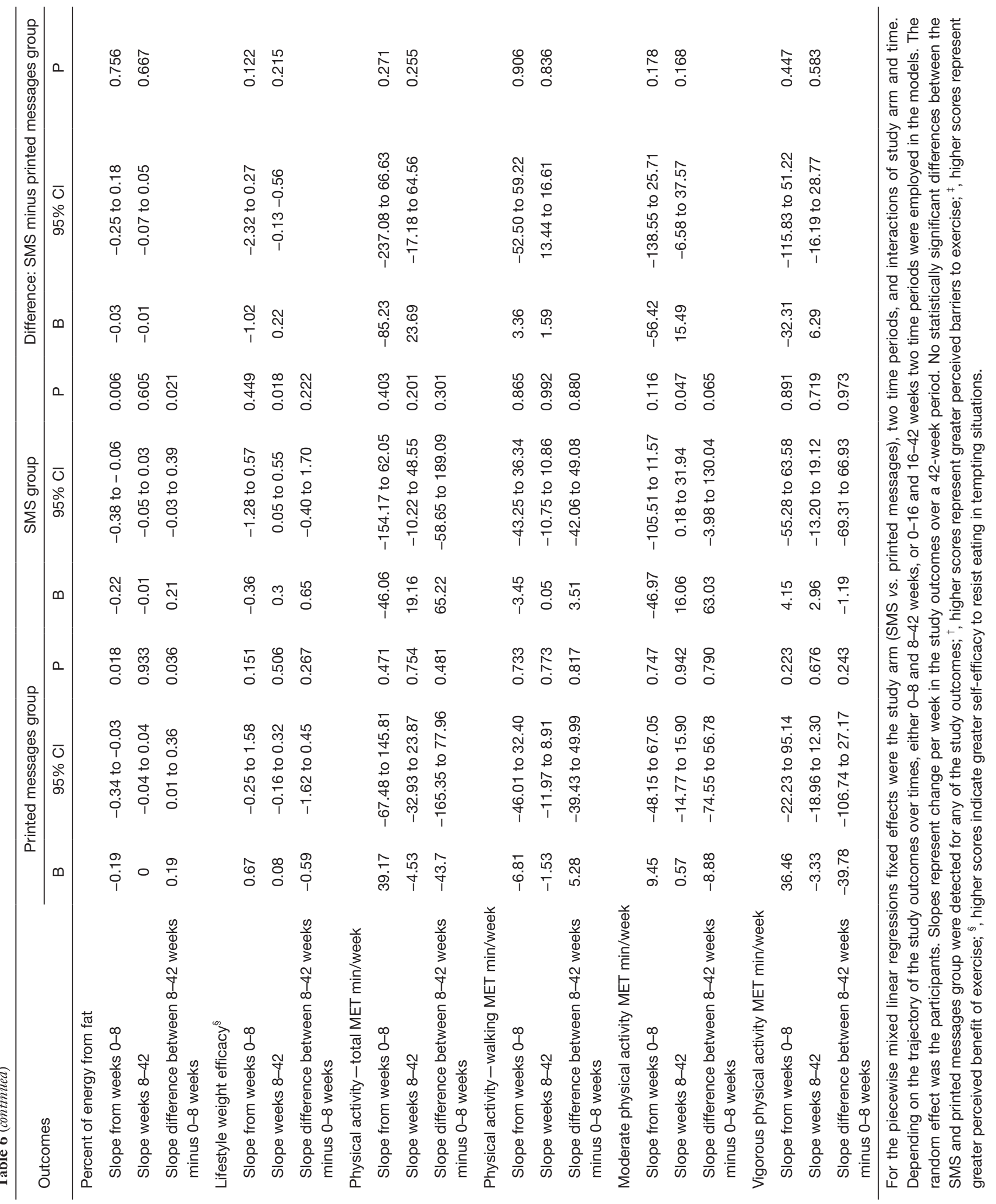


end of the 16-week intervention or 6 months after the completion of the intervention. On average, both the printed messaging and SMS groups experienced small, statistically significant reductions in weight, BMI, and percent energy from fat consumption at the 42 -week assessment compared to baseline. This suggests that both interventions have low efficacy.

A recent systematic review and meta-analysis of SMS weight loss interventions found that the effect of the intervention was generally low (pooled average weight change of $-2.28 \mathrm{~kg}$ after an active intervention period (95\% CI: -3.18 to $-1.39 \mathrm{~kg}$ ); and $-0.68 \mathrm{~kg}$ during the maintenance phase (95\% CI: -1.31 to $-0.05 \mathrm{~kg}$ ) (7). However, interventions of longer duration, and those that included inperson components were more effective (7). Over a 42-week study period, participants in MTRIMM2 SMS group lost an average of $1.19 \mathrm{~kg}$ and participants in the printed messages group lost $0.96 \mathrm{~kg}$. We expected that a $16-w e e k$ intervention was sufficient to result in behavior, because a prior, SMS-enhanced weight loss study conducted in a similar study population in Baltimore, Maryland, found that differences between intervention groups were observed in as little as three months (15). Recent literature reviews suggest that for weight loss interventions, longer intervention duration and greater tailoring of the intervention as well as the addition of nutritional counseling by a registered dietician and exercise counseling may have produced better outcomes (4,7,37-40). Greater intervention tailoring could have been achieved by setting individualized caloric intake targets, developing custom meal plans, allowing participants to set their own goals (instead of picking from three options each week), providing more robust weight loss feedback, and incorporating the use of lifestyle self-monitoring applications into the intervention (40-42).

This study had several limitations. First, we registered the study protocol on clinicaltrials.gov after the data collection was completed. However, the registration occurred before data analysis commenced, and an independent statistician who was not involved in the study design or implementation conducted the regression analyses and verified the interpretation of results. Second, participants self-selected to enroll in the intervention, and therefore the participation was not random, which limits generalizability. Third, the percent weight loss and change in BMI outcomes do not capture changes in body composition and did not allow us to assess whether participants had a reduction in adipose tissue as a result of the intervention. Fourth, the IPAQ questionnaire only asks participants to report activities that they have engaged in for at least 10 minutes at a time. However, the most recent PA guidelines for Americans state that even activities that last fewer than 10 minutes can produce health benefits (43). Furthermore, retrospective measures of PA and diet are subject to recall bias. Fifth, while data collectors were blinded to allocation, they were not blinded to the participants' intervention group assignment after the baseline assessment was completed and participants were randomized. However, we do not expect that this influenced objectively measured outcomes such as weight. Another limitation is that up to 25 participants in the SMS group experienced a two-week interruption in receiving text-messages due to an issue with the Clickatell SMS aggregator. We extended the intervention period for those participants by two weeks, to deliver the missed content. The interruption may have slowed down the momentum participants experienced to engage in healthier behaviors and reduced the intervention's efficacy. Finally, the response rate to text-messages was moderate for the SMS group participants (an overall average of 51.2\%), and greater engagement might have resulted in better outcomes. However, response rate to text-messages might not be a good indicator of engagement because participants were told that responding to the text-messages was optional, and even if they did not pick their weekly goal, a choice would be made for them automatically. In fact, $84.6 \%$ of participants indicated an affirmative response when asked whether they had read most of the messages they received. This percentage was much higher than for the participants in the printed messages group (50.8\%).

This study had several strengths. To our knowledge, this was the first RCT conducted to determine whether a SMS-based weight loss intervention targeting key health behavior decision-making periods during the week results in improved weight loss compared to receiving the same content in paper documents at two follow-up assessments. However, weight loss for the SMS and printed messages group was small, and further research is needed to examine whether more intensive interventions targeting weekly periodicity in health behaviors, with components such as individualized dietary counseling, are more efficacious than interventions that do not take into account weekly periodicity of health behaviors. A second study strength is that because this was an RCT, participants in the intervention and control group were similar in observed, and likely unobserved, characteristics, which reduces the potential for confounding. Third, the study had a relatively long duration and tracked participants during the 16-week 
intervention and 6 months post-intervention completion. This allowed us to assess whether changes in health outcomes that could have resulted from the intervention were sustained after the intervention was completed. In addition, we had good participant retention at 8 -week (94.2\%), 16-week (87.7\%), and 42-week assessments (80.6\%). Finally, the study sample was diverse with regard to age, race, and educational attainment of the study participants. However, future studies should examine the effectiveness of similar SMS interventions in Latinx and in Spanish speaking adults.

In conclusion, in a RCT setting, a text-messaging intervention for the purpose of promoting weight loss among overweight and obese adults was not statistically superior in efficacy to paper-based messaging. Larger studies may be needed to demonstrate superiority of the SMS messaging over paper delivery methods. Further studies are also needed to establish methods that might render the text-messaging intervention more efficacious than traditional paper educational messaging. A promising avenue for future research is to provide messaging which has been more specifically tailored to the characteristics and needs of each participant $(38,42)$. Whether there are differences based on the population characteristics with respect to the efficacy of text-based weight control interventions also needs to be studied.

\section{Acknowledgments}

Funding: This study was funded by the Lerner Center for Public Health Promotion. The Lerner Center for Public Health Promotion was not involved in analysis or interpretation of the study results. AYK received doctoral training funding from the Johns Hopkins CLF-Lerner Fellowship, and a postdoctoral training grant from the National Institutes of Health (5T32HL129953-04). LH received NIH funding (MD012811, NR018916) and funding from the New York Regional Center for Diabetes Translation Research. The content of this manuscript is solely the responsibility of the authors and does not necessarily represent the official views of the National Institutes of Health.

\section{Footnote}

Reporting Checklist: The authors have completed the CONSORT reporting checklist. Available at https://dx.doi. org/10.21037/mhealth-21-3
Trial Protocol: Available at https://dx.doi.org/10.21037/ mhealth-21-3

Data Sharing Statement: Available at https://dx.doi. org/10.21037/mhealth-21-3

Conflicts of Interest: All authors have completed the ICMJE uniform disclosure form (available at https://dx.doi. org/10.21037/mhealth-21-3). This study was funded by Lerner Center for Public Health Promotion, though which AYK, LF, TK, and KW salary support. The Lerner Center for Public Health Promotion was not involved in analysis or interpretation of the study results. AYK received doctoral training funding from the Johns Hopkins CLFLerner Fellowship, and a postdoctoral training grant from the National Institutes of Health (5T32HL129953-04). LH received NIH funding (MD012811, NR018916) and from the New York Regional Center for Diabetes Translation Research. The content of this manuscript is solely the responsibility of the authors and does not necessarily represent the official views of the National Institutes of Health. The other authors have no conflicts of interest to declare.

Ethical Statement: The authors are accountable for all aspects of the work in ensuring that questions related to the accuracy or integrity of any part of the work are appropriately investigated and resolved. The trial was conducted in accordance with the Declaration of Helsinki (as revised in 2013). The study was approved by Johns Hopkins Bloomberg School of Public Health's Institutional Review Board (Federalwide Assurance \#0000287, IRB number: 00007115) and informed consent was taken from all individual participants.

Open Access Statement: This is an Open Access article distributed in accordance with the Creative Commons Attribution-NonCommercial-NoDerivs 4.0 International License (CC BY-NC-ND 4.0), which permits the noncommercial replication and distribution of the article with the strict proviso that no changes or edits are made and the original work is properly cited (including links to both the formal publication through the relevant DOI and the license). See: https://creativecommons.org/licenses/by-nc-nd/4.0/.

\section{References}

1. Hales CM, Fryar CD, Carroll MD, et al. Differences in 
obesity prevalence by demographic characteristics and urbanization level among adults in the United States, 2013-2016. JAMA 2018;319:2419-29.

2. Hales CM, Carroll MD, Fryar CD, et al. Prevalence of obesity among adults and youth: United States, 20152016. NCHS Data Brief 2017:1-8.

3. Baltimore City Department of Health. Baltimore Community Health Survey 2014 report. Baltimore City, MD, 2016.

4. U. S. Preventive Services Task Force, Curry SJ, Krist $\mathrm{AH}$, et al. Behavioral weight loss interventions to prevent obesity-related morbidity and mortality in adults: US Preventive Services Task Force Recommendation statement. JAMA 2018;320:1163-71.

5. LeBlanc ES, Patnode CD, Webber EM, et al. Behavioral and pharmacotherapy weight loss interventions to prevent obesity-related morbidity and mortality in adults: updated evidence report and systematic review for the US Preventive Services Task Force. JAMA 2018;320:1172-91.

6. Pew Research Center. Mobile Fact Sheet. 2019. Available online: https://www.pewresearch.org/internet/fact-sheet/ mobile/. Accessed 08/26/2020.

7. Skinner R, Gonet V, Currie S, et al. A systematic review with meta-analyses of text message-delivered behaviour change interventions for weight loss and weight loss maintenance. Obes Rev 2020;21:e12999.

8. Rathbone AL, Prescott J. The use of mobile apps and SMS messaging as physical and mental health interventions: systematic review. J Med Internet Res 2017;19:e295.

9. Rogers E, Aidasani SR, Friedes R, et al. Barriers and facilitators to the implementation of a mobile insulin titration intervention for patients with uncontrolled diabetes: a qualitative analysis. JMIR Mhealth Uhealth 2019;7:e13906.

10. Hill C, Weir BW, Fuentes LW, et al. Relationship between weekly patterns of caloric intake and reported weight loss outcomes: retrospective cohort study. JMIR Mhealth Uhealth 2018;6:e83.

11. Yang PH, Black JL, Barr SI, et al. Examining differences in nutrient intake and dietary quality on weekdays versus weekend days in Canada. Appl Physiol Nutr Metab 2014;39:1413-7.

12. Ayers JW, Althouse BM, Johnson M, et al. What's the healthiest day? Circaseptan (weekly) rhythms in healthy considerations. Am J Prev Med 2014;47:73-6.

13. Orsama AL, Mattila E, Ermes M, et al. Weight rhythms: weight increases during weekends and decreases during weekdays. Obes Facts 2014;7:36-47.
14. Mattila E, Lappalainen R, Parkka J, et al. Use of a mobile phone diary for observing weight management and related behaviours. J Telemed Telecare 2010;16:260-4.

15. Lin $M$, Mahmooth Z, Dedhia N, et al. Tailored, interactive text messages for enhancing weight loss among African American adults: the TRIMM randomized controlled trial. Am J Med 2015;128:896-904.

16. Prochaska JO, Velicer WF. The transtheoretical model of health behavior change. American Journal of Health Promotion 1997;12:38-48.

17. Janz NK, Becker MH. The Health Belief Model: a decade later. Health Education Quarterly 1984;11:1-47.

18. Baumeister RF, Vohs KD. Strength Model of SelfRegulation as limited resource: assessment, controversies, update. In: Olson JM, Zanna MP, editors. Advances in Experimental Social Psychology, Vol 54. Advances in Experimental Social Psychology. San Diego: Elsevier Academic Press Inc; 2016:67-127.

19. Rosenstock IM, Strecher VJ, Becker MH. Social learning theory and the Health Belief Model. Health Educ Q 1988;15:175-83.

20. Centers for Disease Control and Prevention. Physical activity and health: a report of the Surgeon General. Atlanta, Georgia. 1996. Available online: https://www.cdc. gov/nccdphp/sgr/pdf/sgraag.pdf. Accessed 12/09/2020.

21. American Diabetes Association. The Best Food Choices. Arlington, VA, 2015.

22. American Diabetes Association. What can I eat? Arlington, VA, 2015.

23. Harris PA, Taylor R, Thielke R, et al. Research electronic data capture (REDCap)--a metadata-driven methodology and workflow process for providing translational research informatics support. J Biomed Inform 2009;42:377-81.

24. Harris PA, Taylor R, Minor BL, et al. The REDCap consortium: building an international community of software platform partners. J Biomed Inform 2019;95:103208.

25. National Institutes of Health. National Institutes of Health Eating at America's Table Study Quick Food Scan. 2000. Available online: https://epi.grants.cancer. gov/diet/shortreg/instruments/eats_all-day.pdf. Accessed 08/06/2020.

26. Subar AF, Thompson FE, Kipnis V, et al. Comparative validation of the Block, Willett, and National Cancer Institute food frequency questionnaires : the Eating at America's Table Study. Am J Epidemiol 2001;154:1089-99.

27. Thompson FE, Subar AF, Smith AF, et al. Fruit and vegetable assessment: performance of 2 new short 
instruments and a food frequency questionnaire. J Am Diet Assoc 2002;102:1764-72.

28. National Cancer Institute. Scoring the All-Day Screener. 2005. Available online: https://epi.grants.cancer.gov/diet/ screeners/fruitveg/scoring/allday.html\#how. Accessed 08/06/2020.

29. National Cancer Institute. National Cancer Institute Quick Food Scan: Percent Energy from Fat Screener. 2000. Available online: https://epi.grants.cancer.gov/diet/ shortreg/instruments/percent-energy-from-fat-screener. pdf. Accessed 08/06/2020.

30. Thompson FE, Midthune D, Subar AF, et al. Development and evaluation of a short instrument to estimate usual dietary intake of percentage energy from fat. J Am Diet Assoc 2007;107:760-7.

31. Thompson FE, Midthune D, Williams GC, et al. Evaluation of a short dietary assessment instrument for percentage energy from fat in an intervention study. J Nutr 2008;138:193S-9S.

32. National Cancer Institute. Percentage Energy from Fat Screener: scoring procedures. 2004. Available online: https://epi.grants.cancer.gov/diet/screeners/fat/scoring. html. Accessed 08/06/2020 2020.

33. Booth $M$. Assessment of physical activity: an international perspective. Res Q Exerc Sport 2000;71 Suppl 2:114-20.

34. IPAQ Research Committee. Guidelines for the data processing and analysis of the International Physical Activity Questionnaire. 2005. Available online: https:// sites.google.com/site/theipaq/scoring-protocol. Accessed 08/06/2020.

35. Clark MM, Abrams DB, Niaura RS, et al. Selfefficacy in weight management. J Consult Clin Psychol

doi: $10.21037 /$ mhealth-21-3

Cite this article as: Kharmats AY, Wang C, Fuentes L, Hu L, Kline T, Welding K, Cheskin LJ. Monday-focused tailored rapid interactive mobile messaging for weight management 2 (MTRIMM2): results from a randomized controlled trial. mHealth 2022;8:1.
1991;59:739-44.

36. Sechrist KR, Walker SN, Pender NJ. Development and psychometric evaluation of the exercise benefits/barriers scale. Res Nurs Health 1987;10:357-65.

37. Singh N, Stewart RAH, Benatar JR. Intensity and duration of lifestyle interventions for long-term weight loss and association with mortality: a meta-analysis of randomised trials. BMJ Open 2019;9:e029966.

38. Ryan K, Dockray S, Linehan C. A systematic review of tailored eHealth interventions for weight loss. Digit Health 2019;5:2055207619826685.

39. Ahern AL, Wheeler GM, Aveyard P, et al. Extended and standard duration weight-loss programme referrals for adults in primary care (WRAP): a randomised controlled trial. Lancet 2017;389:2214-25.

40. Sherrington A, Newham JJ, Bell R, et al. Systematic review and meta-analysis of internet-delivered interventions providing personalized feedback for weight loss in overweight and obese adults. Obes Rev 2016;17:541-51.

41. Cavero-Redondo I, Martinez-Vizcaino V, FernandezRodriguez R, et al. Effect of behavioral weight management interventions using lifestyle mHealth selfmonitoring on weight loss: a systematic review and metaanalysis. Nutrients 2020;12:1977.

42. De Leon E, Fuentes LW, Cohen JE. Characterizing periodic messaging interventions across health behaviors and media: systematic review. J Med Internet Res 2014;16:e93.

43. U.S. Department of Health and Human Services. Physical Activity Guidelines for Americans, 2nd edition. Washington, DC: U.S., 2018. 


\section{Supplementary}

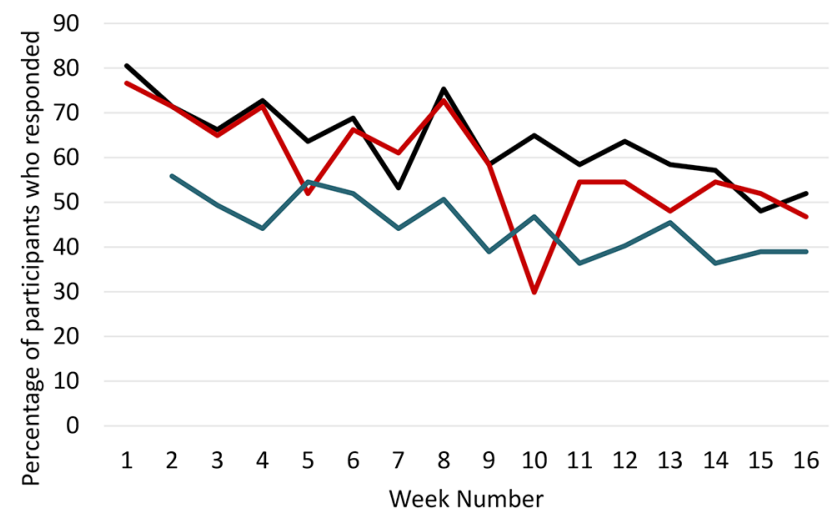

\section{- Selected weekly goal}

Responded about whether they made a plan to reach weekly goal

\section{Sent their weight}

Note. Due to an unknown error, during the first week of the text-messaging intervention, all participants' weight was incorrectly recorded as 100 pounds, which did not allow for an estimation of response rate to the weight question for the first week of the intervention.

Figure S1 Percentage of participants who responded to text-messages that asked questions.

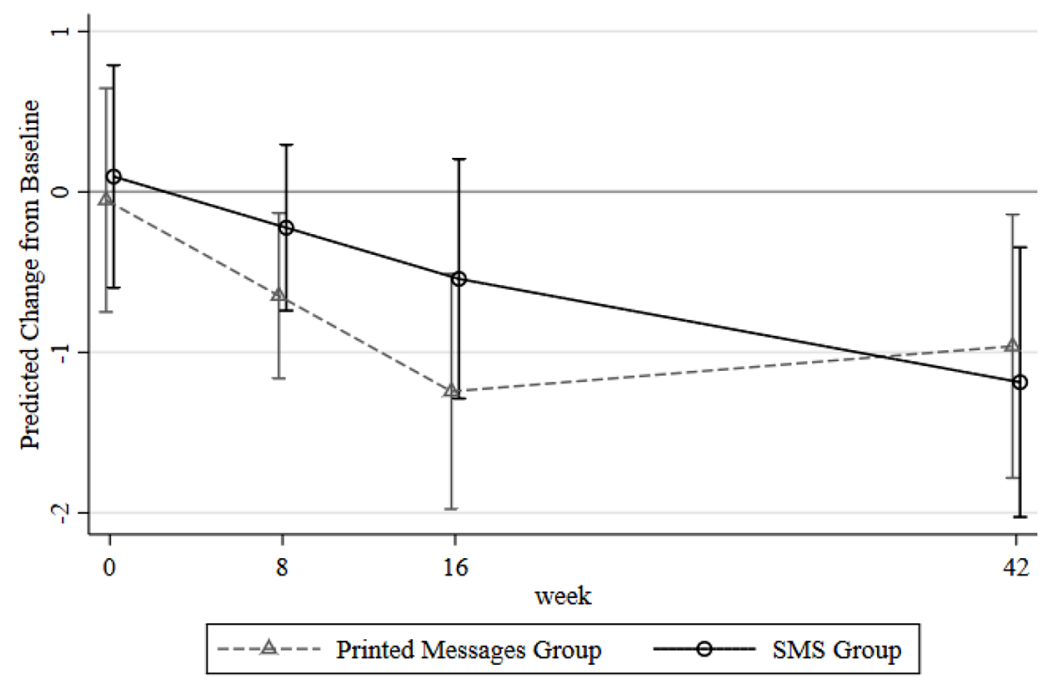

Figure S2 Results of piecewise linear mixed model: average change in weight ( $\mathrm{kgs})$ from baseline in the SMS and printed messaging groups with $95 \%$ confidence intervals. SMS, short messaging service. 


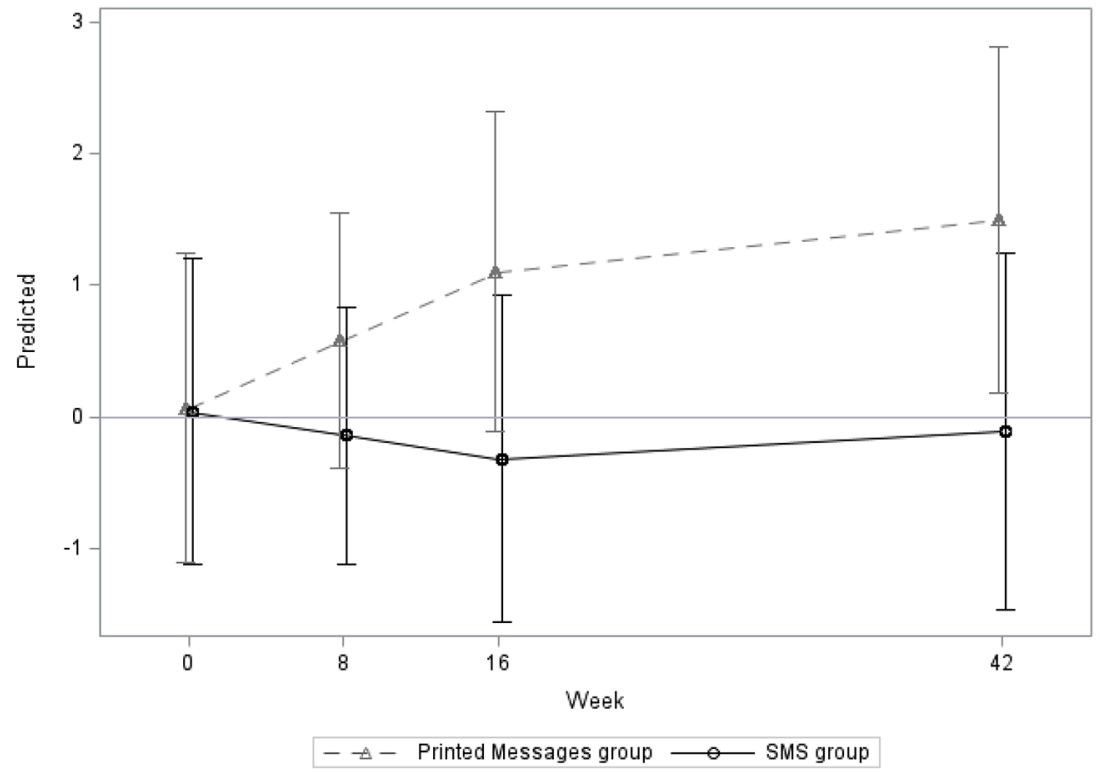

Note. Higher scores on the Exercise Barriers Scale represent greater perceived barriers to exercise.

Figure S3 Results of piecewise linear mixed model: average differences in exercise barriers from baseline in the SMS and printed messaging groups with $95 \%$ confidence interval. SMS, short messaging service.

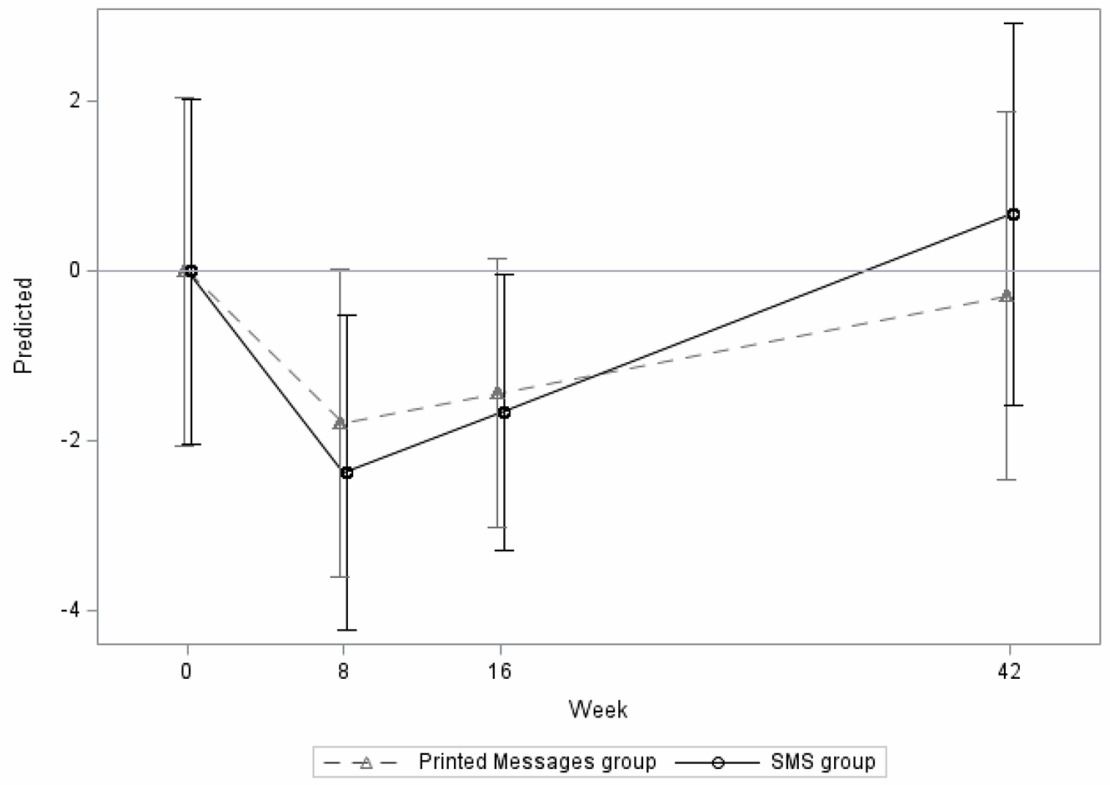

Note. Higher scores on the Exercise Benefit Scale represent greater perceived benefit of exercise.

Figure S4 Results of piecewise linear mixed model: average differences in exercise benefit from baseline in the SMS and printed messaging groups with $95 \%$ confidence intervals. SMS, short messaging service. 


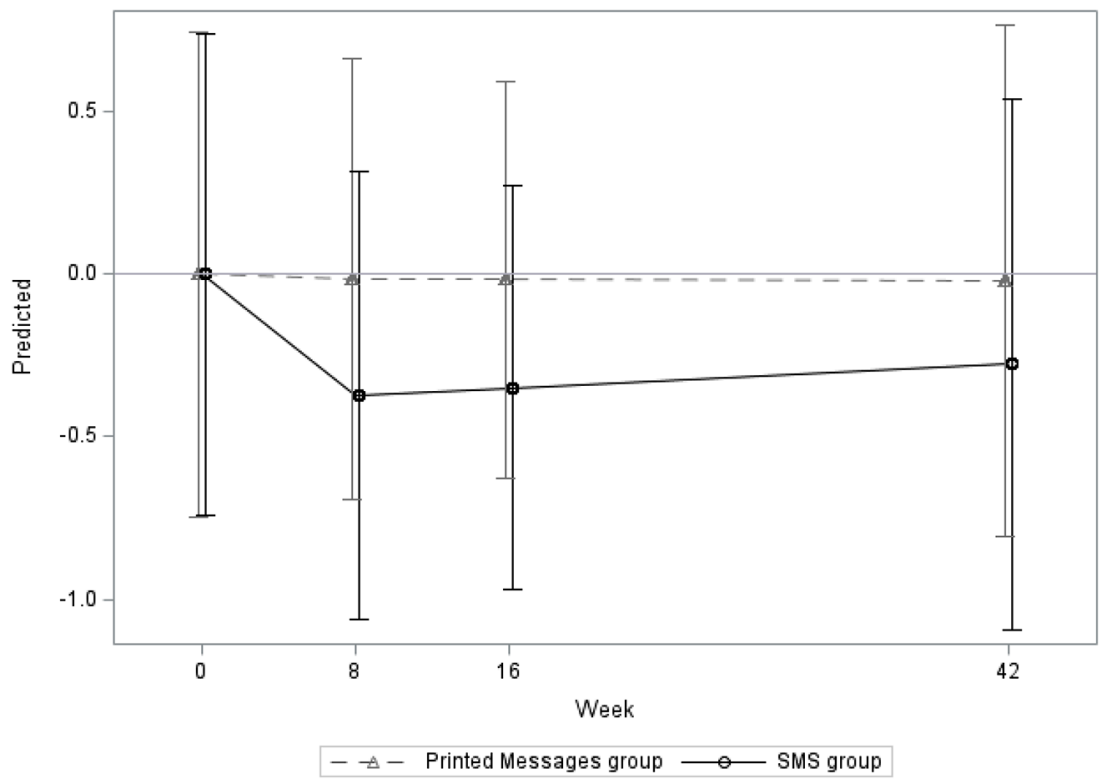

Figure S5 Results of piecewise linear mixed model: average differences in daily servings of fruits and vegetables consumed (excluding potatoes) from baseline in the SMS and printed messaging groups with 95\% confidence intervals. SMS, short messaging service.

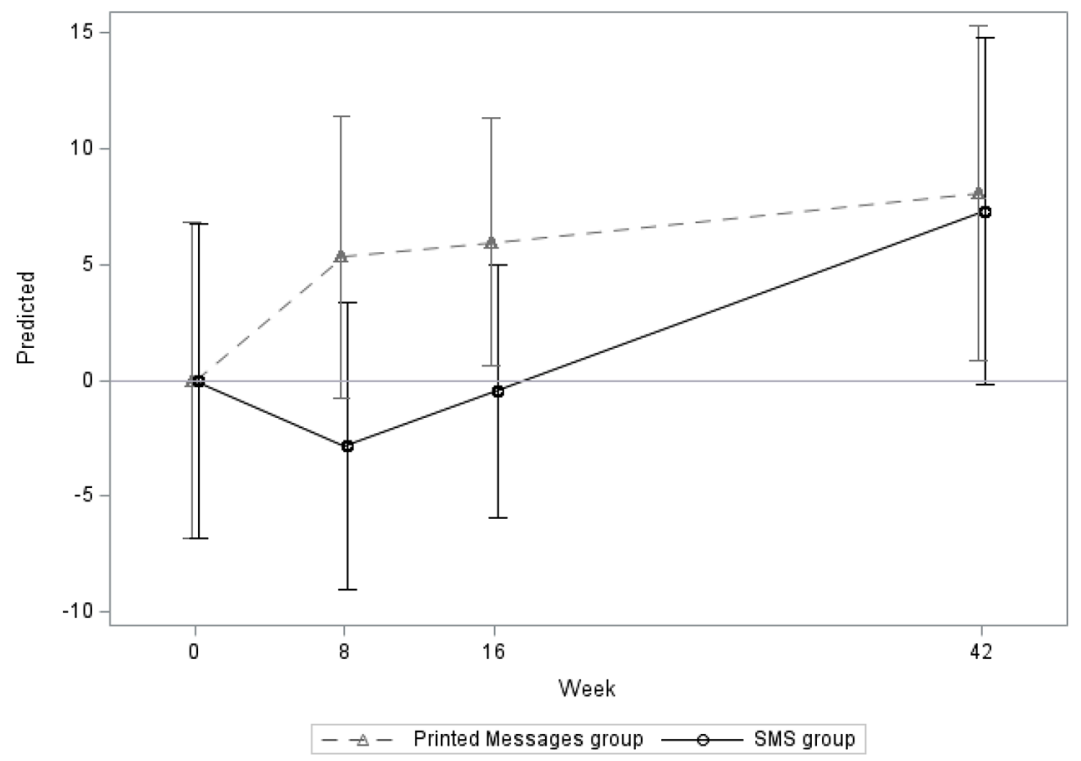

Note. Higher scores on the Weight Efficacy Questionnaire indicate greater self-efficacy to resist eating in tempting situations.

Figure S6 Results of piecewise linear mixed model: average differences in lifestyle weight efficacy from baseline in the SMS and printed messaging groups with $95 \%$ confidence intervals. SMS, short messaging service. 


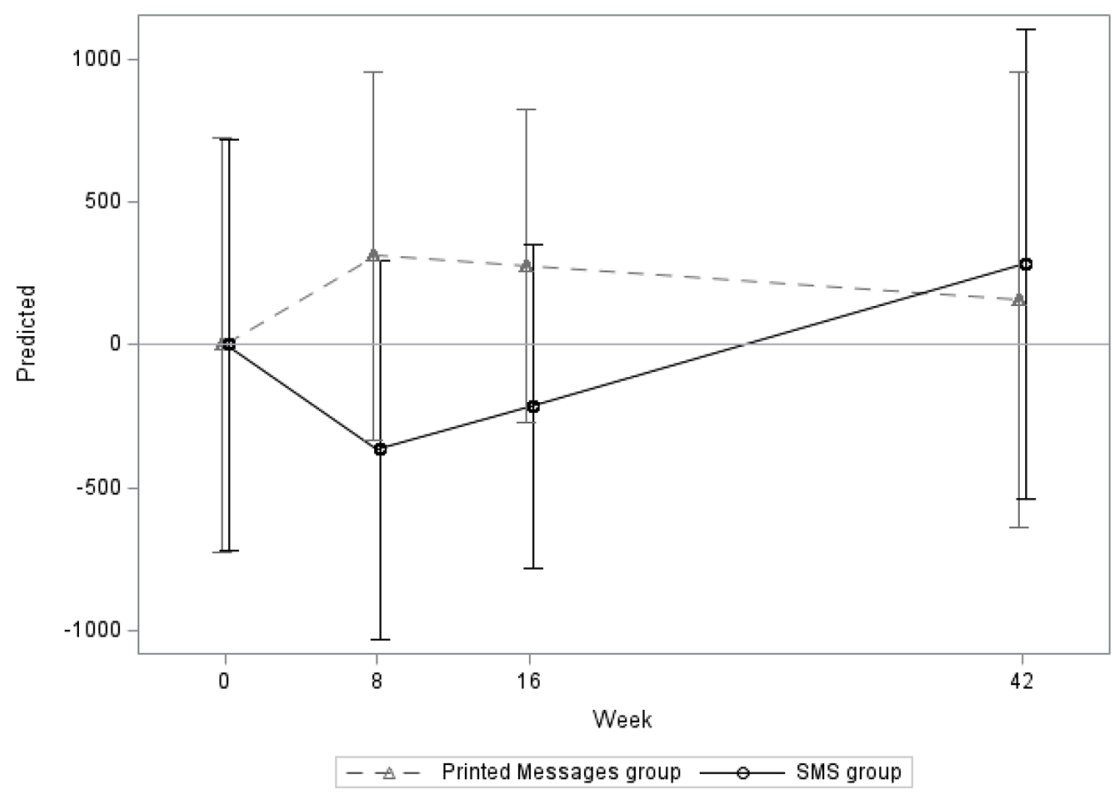

Figure S7 Results of piecewise linear mixed model: average differences in physical activity-total MET mins/week from baseline in the SMS and printed messaging groups with $95 \%$ confidence intervals. SMS, short messaging service.

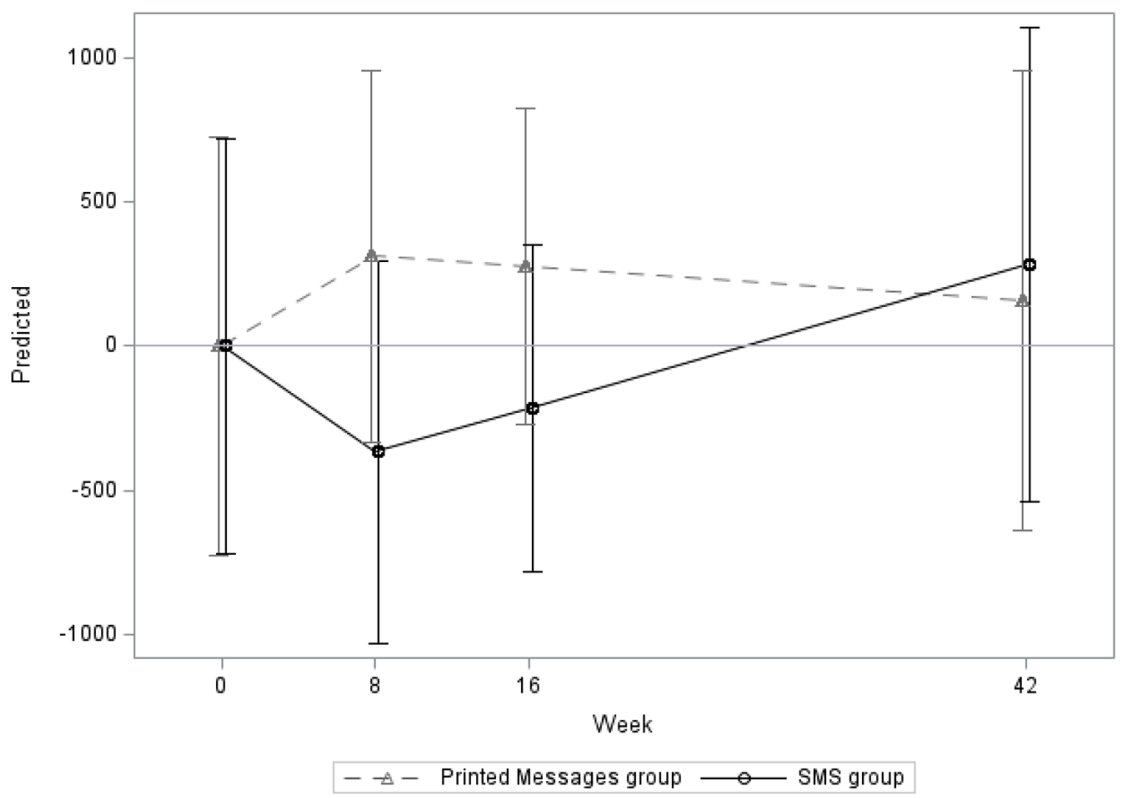

Figure S8 Results of piecewise linear mixed model: average differences in physical activity-walking MET mins/week from baseline in the SMS and printed messaging groups with $95 \%$ confidence intervals. SMS, short messaging service. 


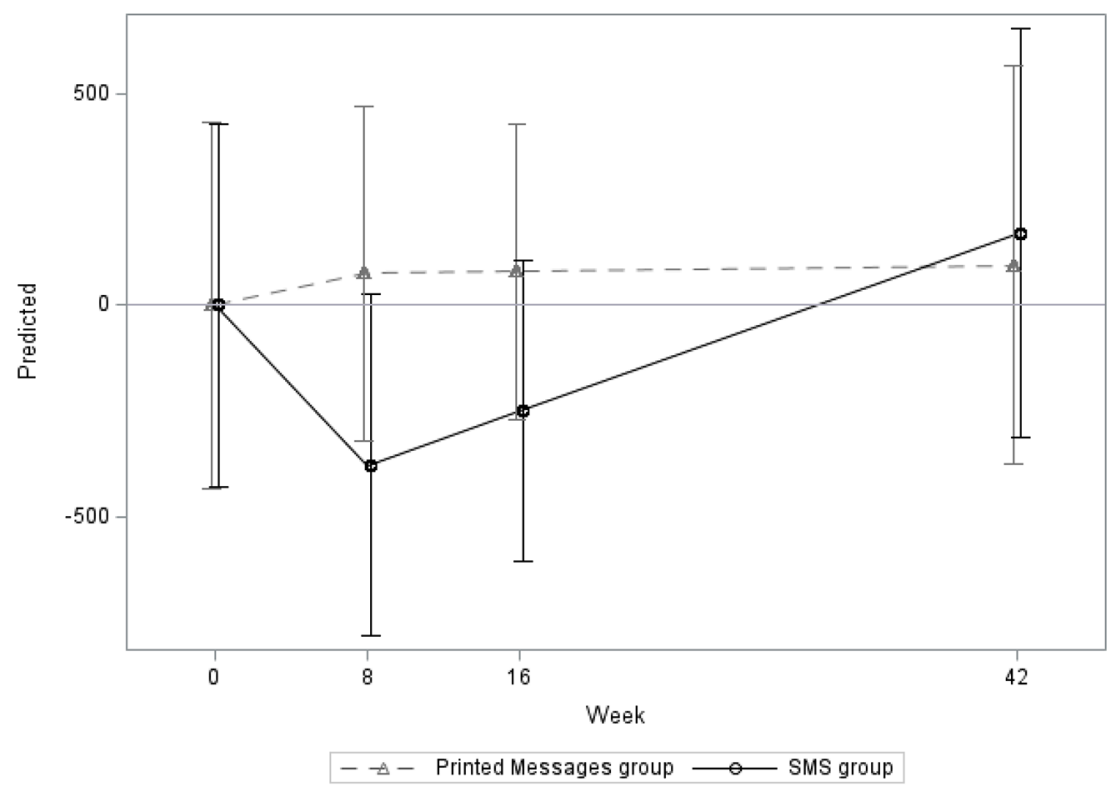

Figure S9 Results of piecewise linear mixed model: average differences in moderate physical activity MET mins/week from baseline in the SMS and printed messaging groups with $95 \%$ confidence intervals. SMS, short messaging service.

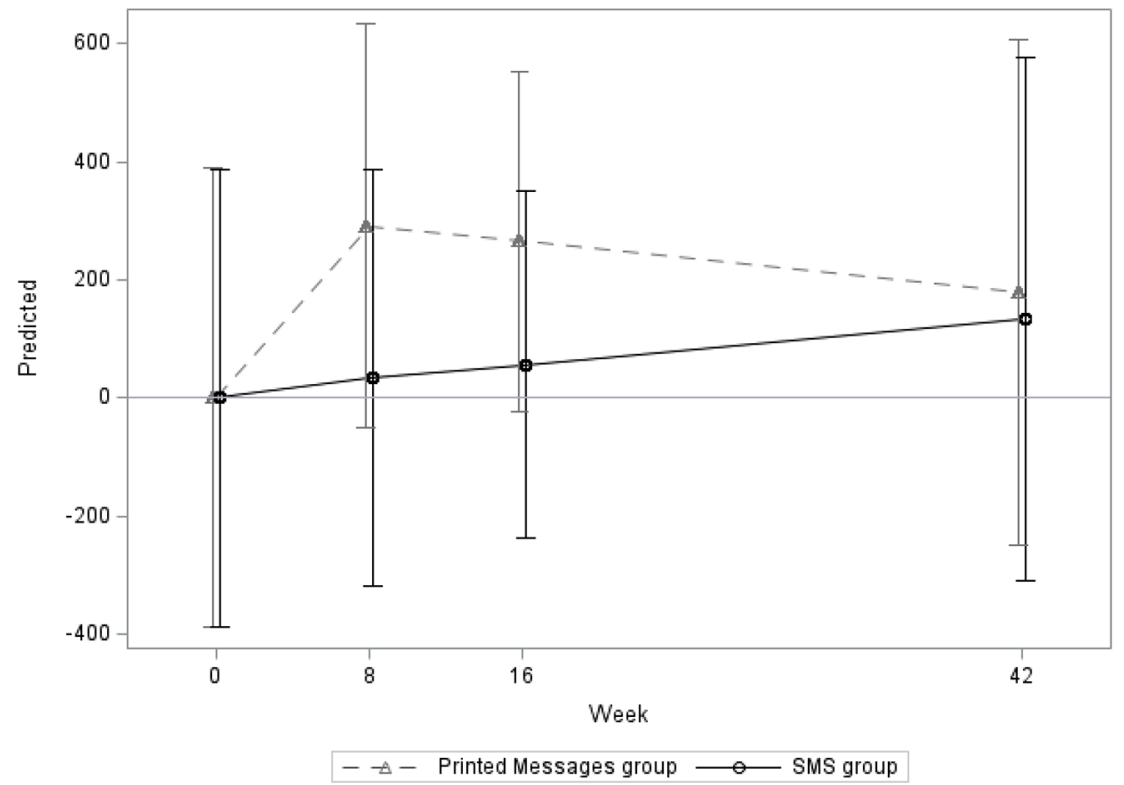

Figure S10 Results of piecewise linear mixed model: average differences vigorous physical activity MET mins/week from baseline in the SMS and printed messaging groups with $95 \%$ confidence intervals. SMS, short messaging service. 
Table S1 Results of mixed linear regressions using intention to treat analysis: weekly changes in MTRIMM2 outcomes over 42 weeks

\begin{tabular}{|c|c|c|c|c|c|c|c|c|c|}
\hline \multirow{2}{*}{ Outcomes } & \multicolumn{3}{|c|}{ Printed Messages Group } & \multicolumn{3}{|c|}{ SMS Group } & \multicolumn{3}{|c|}{ Difference: SMS minus Printed Messaging Group } \\
\hline & B & $95 \% \mathrm{Cl}$ & $\mathrm{p}$ & B & $95 \% \mathrm{Cl}$ & $\mathrm{p}$ & B & $95 \% \mathrm{Cl}$ & $\mathrm{p}$ \\
\hline \multicolumn{10}{|c|}{ Weekly Change in Weight (in kgs) from Baseline } \\
\hline & -0.019 & $-0.042-0.005$ & 0.116 & -0.030 & $-0.054--0.006$ & 0.013 & -0.011 & $-0.044-0.022)$ & 0.506 \\
\hline \multicolumn{10}{|c|}{ Percent Weight Lost from Baseline Weight per Week } \\
\hline & -0.016 & $-0.040-0.008$ & 0.190 & -0.031 & $-0.055--0.006$ & 0.014 & -0.015 & $-0.049-0.020$ & 0.402 \\
\hline \multicolumn{10}{|c|}{ Weekly BMI Change from Baseline } \\
\hline & -0.007 & $-0.015-0.002$ & 0.142 & -0.013 & $-0.022--0.004$ & 0.005 & -0.006 & $-0.019-0.006$ & 0.319 \\
\hline \multicolumn{10}{|c|}{ Weekly Exercise Barriers Score Change from Baseline ${ }^{\dagger}$} \\
\hline & 0.032 & $0.000-0.064$ & 0.050 & -0.003 & $-0.036-0.031$ & 0.880 & -0.035 & $-0.081-0.012$ & 0.141 \\
\hline \multicolumn{10}{|c|}{ Weekly Exercise Benefit Score Change from Baseline ${ }^{\ddagger}$} \\
\hline & 0.007 & $-0.052-0.066$ & 0.817 & 0.034 & $-0.026-0.095$ & 0.268 & 0.027 & $-0.057-0.112$ & 0.525 \\
\hline \multicolumn{10}{|c|}{ Weekly Change in Average Number of Fruit and Vegetable Servings Consumed per Day Excluding Potatoes } \\
\hline & 0.000 & $-0.020-0.019$ & 0.965 & -0.004 & $-0.025-0.016$ & 0.673 & -0.004 & $-0.032-0.024$ & 0.784 \\
\hline \multicolumn{10}{|c|}{ Weekly Change in Percent of Energy from Fat Consumed: Change from Baseline } \\
\hline & -0.024 & $-0.057-0.008$ & 0.139 & -0.041 & $-0.075--0.008$ & 0.016 & -0.017 & $-0.063-0.030$ & 0.483 \\
\hline \multicolumn{10}{|c|}{ Weekly Change in Lifestyle Weight Efficacy Score from Baseline ${ }^{\S}$} \\
\hline & 0.163 & $-0.027-0.353$ & 0.093 & 0.205 & $0.008-0.401$ & 0.041 & 0.042 & $-0.232-0.315$ & 0.763 \\
\hline \multicolumn{10}{|c|}{ Weekly Change in Physical Activity - Total MET mins/week from Baseline } \\
\hline & 1.720 & $-20.710-24.150$ & 0.880 & 9.551 & $-13.467-32.568$ & 0.415 & 7.831 & $-24.308-39.970$ & 0.632 \\
\hline \multicolumn{10}{|c|}{ Weekly Change in Physical Activity - Walking MET mins/week from Baseline } \\
\hline & -2.285 & $-10.524-5.954$ & 0.586 & -0.464 & $-8.926-7.998$ & 0.914 & 1.821 & $-9.990-13.631$ & 0.762 \\
\hline \multicolumn{10}{|c|}{ Weekly Change in Moderate Physical Activity MET mins/week from Baseline } \\
\hline & 1.832 & $-10.332-13.997$ & 0.767 & 6.829 & $-5.675-19.333$ & 0.284 & 4.997 & $-12.448-22.442$ & 0.574 \\
\hline \multicolumn{10}{|c|}{ Weekly Change in Vigorous Physical Activity MET mins/week from Baseline } \\
\hline & 2.367 & $-9.966-14.700$ & 0.706 & 3.137 & $-9.510-15.783$ & 0.626 & 0.769 & $-16.895-18.434$ & 0.932 \\
\hline
\end{tabular}

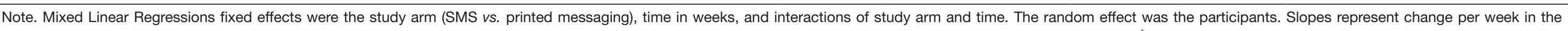

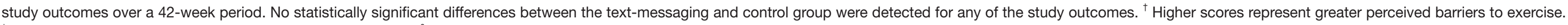
${ }^{\ddagger}$ Higher scores represent greater perceived benefit of exercise. ${ }^{\S}$ Higher scores indicate greater self-efficacy to resist eating in tempting situations. SMS, short messaging service. 
Table S2 Results of mixed linear regressions using intention to treat analysis: changes in MTRIMM2 outcomes over 42 weeks as a function of response rate to SMS messages for participants in the SMS group

\begin{tabular}{|c|c|c|c|c|c|c|c|c|c|}
\hline \multirow{2}{*}{ Outcomes } & \multicolumn{3}{|c|}{ Response rate to text messages (\%) } & \multicolumn{3}{|c|}{ Week } & \multicolumn{3}{|c|}{ Interaction between Week and Response Rate to SMS Messages } \\
\hline & B & $95 \% \mathrm{Cl}$ & $\mathrm{p}$ & B & $95 \% \mathrm{Cl}$ & $\mathrm{p}$ & B & $95 \% \mathrm{Cl}$ & $\mathrm{p}$ \\
\hline \multicolumn{10}{|c|}{ Weekly Change in Weight (in kgs) from Baseline } \\
\hline & -0.001 & $-0.023-0.021$ & 0.944 & 0.012 & $-0.042-0.066$ & 0.669 & -0.001 & $-0.002-0.000$ & 0.106 \\
\hline \multicolumn{10}{|c|}{ Percent Weight Lost from Baseline Weight per Week } \\
\hline & -0.002 & $-0.026-0.021$ & 0.840 & 0.022 & $-0.035-0.080$ & 0.442 & -0.001 & $-0.002-0.000$ & 0.054 \\
\hline \multicolumn{10}{|c|}{ Weekly BMI Change from Baseline } \\
\hline & 0.000 & $-0.009-0.008$ & 0.911 & 0.003 & $-0.018-0.023$ & 0.779 & 0.000 & $-0.001-0.000$ & 0.104 \\
\hline \multicolumn{10}{|c|}{ Weekly Exercise Barriers Score Change from Baseline ${ }^{\dagger}$} \\
\hline & -0.014 & $-0.066-0.037$ & 0.578 & 0.074 & $-0.019-0.168$ & 0.120 & -0.001 & $-0.003-0.00$ & 0.088 \\
\hline \multicolumn{10}{|c|}{ Weekly Exercise Benefit Score Change from Baseline ${ }^{\ddagger}$} \\
\hline & -0.009 & $-0.082-0.063$ & 0.796 & 0.043 & $-0.120-0.207$ & 0.602 & 0.000 & $-0.003-0.003$ & 0.908 \\
\hline \multicolumn{10}{|c|}{ Weekly Change in Average Number of Fruit and Vegetable Servings Consumed per Day Excluding Potatoes } \\
\hline & 0.017 & $-0.010-0.044$ & 0.220 & -0.018 & $-0.073-0.037$ & 0.526 & 0.000 & $-0.001-0.001$ & 0.627 \\
\hline \multicolumn{10}{|c|}{ Weekly Change in Percent of Energy from Fat Consumed: Change from Baseline } \\
\hline & 0.005 & $-0.031-0.041$ & 0.798 & -0.064 & $-0.134-0.005$ & 0.069 & 0.000 & $-0.001-0.002$ & 0.479 \\
\hline \multicolumn{10}{|c|}{ Weekly Change in Lifestyle Weight Efficacy Score from Baseline ${ }^{\S}$} \\
\hline & -0.031 & $-0.245-0.182$ & 0.770 & 0.491 & $0.053-0.928$ & 0.028 & -0.005 & $-0.013-0.002$ & 0.170 \\
\hline \multicolumn{10}{|c|}{ Weekly Change in Physical Activity - Total MET mins/week from Baseline } \\
\hline & -12.698 & $-40.956-15.560$ & 0.374 & 42.242 & $-23.306-107.790$ & 0.205 & -0.581 & $-1.697-0.534$ & 0.305 \\
\hline \multicolumn{10}{|c|}{ Weekly Change in Physical Activity - Walking MET mins/week from Baseline } \\
\hline & 1.005 & $-8.931-10.941$ & 0.841 & 4.822 & $-17.589-27.232$ & 0.672 & -0.097 & $-0.478-0.284$ & 0.616 \\
\hline \multicolumn{10}{|c|}{ Weekly Change in Moderate Physical Activity MET mins/week from Baseline } \\
\hline & -6.040 & $-22.370-10.289$ & 0.464 & 45.649 & $11.564-79.734$ & 0.009 & -0.700 & $-1.280--0.121$ & 0.018 \\
\hline \multicolumn{10}{|c|}{ Weekly Change in Vigorous Physical Activity MET mins/week from Baseline } \\
\hline & -7.844 & $-20.720-5.031$ & 0.229 & -7.118 & $-40.381-26.145$ & 0.673 & 0.200 & $-0.367-0.767$ & 0.488 \\
\hline
\end{tabular}

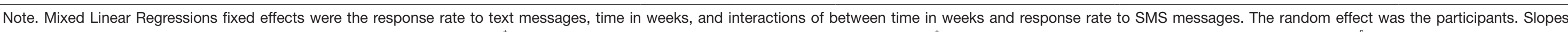

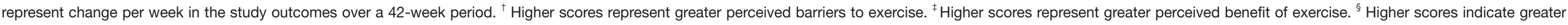
self-efficacy to resist eating in tempting situations. SMS, short messaging service. 
Table S3 Sensitivity analysis: results of piecewise mixed linear regressions as treated analysis-weekly changes in MTRIMM2 outcomes over 42 weeks

\begin{tabular}{|c|c|c|c|c|c|c|c|c|c|}
\hline \multirow{2}{*}{ Outcomes } & \multicolumn{3}{|c|}{ Printed Messages Group } & \multicolumn{3}{|c|}{ SMS Group } & \multicolumn{3}{|c|}{ Difference: SMS minus Printed Messages Group } \\
\hline & $\mathrm{B}$ & $(95 \% \mathrm{Cl})$ & $\mathrm{p}$ & $\mathrm{B}$ & $(95 \% \mathrm{Cl})$ & $\mathrm{p}$ & $\mathrm{B}$ & $(95 \% \mathrm{Cl})$ & $\mathrm{p}$ \\
\hline \multicolumn{10}{|l|}{ Weight Lost (kgs) per week } \\
\hline Slope from Weeks $0-16$ & -0.07 & $(-0.14--0.01)$ & 0.017 & -0.04 & $(-0.10-0.02)$ & 0.209 & 0.03 & $(-0.05-0.12)$ & 0.425 \\
\hline Slope Weeks $16-42$ & 0.01 & $(-0.03-0.05)$ & 0.580 & -0.02 & $(-0.06-0.01)$ & 0.215 & -0.04 & $(-0.09-0.02)$ & 0.203 \\
\hline $\begin{array}{l}\text { Slope difference between } 16-42 \text { weeks minus 0-16 } \\
\text { weeks }\end{array}$ & 0.09 & $(-0.00-0.17)$ & 0.055 & 0.01 & $(-0.07-0.10)$ & 0.742 & -0.07 & $(-0.19-0.05)$ & 0.263 \\
\hline \multicolumn{10}{|l|}{ Percent of Baseline Weight Lost per week } \\
\hline Slope from Weeks $0-16$ & -0.08 & $(-0.14--0.01)$ & 0.017 & -0.04 & $(-0.11-0.02)$ & 0.182 & 0.03 & $(-0.05-0.12)$ & 0.464 \\
\hline Slope Weeks $16-4$ & 0.02 & $(-0.02-0.05)$ & 0.448 & -0.02 & $(-0.06-0.02)$ & 0.257 & -0.04 & $(-0.09-0.02)$ & 0.180 \\
\hline $\begin{array}{l}\text { Slope difference between } 16-42 \text { weeks minus 0-16 } \\
\text { weeks }\end{array}$ & 0.09 & $(0.00-0.18)$ & 0.046 & 0.02 & $(-0.07-0.11)$ & 0.667 & -0.07 & $(-0.20-0.06)$ & 0.270 \\
\hline \multicolumn{10}{|l|}{ BMI change per week } \\
\hline Slope from Weeks $0-16$ & -0.03 & $(-0.05--0.01)$ & 0.011 & -0.01 & $(-0.04-0.01)$ & 0.274 & 0.02 & $(-0.02-0.05)$ & 0.311 \\
\hline Slope Weeks $16-42$ & 0.01 & $(-0.01-0.02)$ & 0.449 & -0.01 & $(-0.03-0.00)$ & 0.092 & -0.02 & $(-0.04-0.00)$ & 0.083 \\
\hline $\begin{array}{l}\text { Slope difference between } 16-42 \text { weeks minus 0-16 } \\
\text { weeks }\end{array}$ & 0.04 & $(0.00-0.07)$ & 0.035 & 0.00 & $(-0.03-0.03)$ & 0.983 & -0.04 & $(-0.08-0.01)$ & 0.141 \\
\hline \multicolumn{10}{|l|}{ Exercise Barriers $^{\dagger}$} \\
\hline Slope from Weeks $0-16$ & 0.07 & $(-0.02-0.15)$ & 0.121 & -0.03 & $(-0.11-0.06)$ & 0.565 & -0.09 & $(-0.21-0.03)$ & 0.132 \\
\hline Slope Weeks $16-42$ & 0.01 & $(-0.04-0.07)$ & 0.582 & 0.01 & $(-0.05-0.06)$ & 0.761 & -0.01 & $(-0.08-0.07)$ & 0.871 \\
\hline $\begin{array}{l}\text { Slope difference between } 16-42 \text { weeks minus 0-16 } \\
\text { weeks }\end{array}$ & -0.05 & $(-0.17-0.07)$ & 0.393 & 0.03 & $(-0.09-0.16)$ & 0.591 & 0.09 & $(-0.09-0.26)$ & 0.324 \\
\hline \multicolumn{10}{|l|}{ Exercise Benefit ${ }^{\ddagger}$} \\
\hline Slope from Weeks $0-8$ & -0.22 & $(-0.46-0.02)$ & 0.075 & -0.26 & $(-0.47--0.06)$ & 0.013 & -0.04 & $(-0.24-0.15)$ & 0.665 \\
\hline Slope Weeks $8-42$ & 0.04 & $(-0.03-0.11)$ & 0.243 & 0.11 & $(0.01-0.21)$ & 0.025 & 0.07 & $(-0.05-0.20)$ & 0.258 \\
\hline Slope difference between 8- 42 weeks minus 0-8 weeks & 0.26 & $(-0.01-0.53)$ & 0.061 & 0.38 & $(0.12-0.63)$ & 0.004 & 0.12 & $(-0.16-0.39)$ & 0.404 \\
\hline \multicolumn{10}{|c|}{ Average Number of Fruit and Vegetable Servings Consumed per Day Excluding Potatoes } \\
\hline Slope from Weeks $0-8$ & -0.02 & $(-0.10-0.06)$ & 0.581 & -0.03 & $(-0.09-0.04)$ & 0.465 & -0.00 & $(-0.07-0.06)$ & 0.927 \\
\hline Slope Weeks $8-42$ & 0.00 & $(-0.02-0.03)$ & 0.772 & -0.00 & $(-0.03-0.03)$ & 0.935 & -0.00 & $(-0.05-0.04)$ & 0.824 \\
\hline Slope difference between 8- 42 weeks minus $0-8$ weeks & 0.03 & $(-0.06-0.12)$ & 0.574 & 0.02 & $(-0.06-0.11)$ & 0.574 & -0.00 & $(-0.09-0.09)$ & 0.970 \\
\hline \multicolumn{10}{|l|}{ Percent of Energy from Fat } \\
\hline Slope from Weeks $0-8$ & -0.19 & $(-0.32--0.05)$ & 0.006 & -0.22 & $(-0.33--0.10)$ & 0.000 & -0.03 & $(-0.14-0.08)$ & 0.606 \\
\hline Slope Weeks $8-42$ & 0.00 & $(-0.03-0.04)$ & 0.809 & -0.01 & $(-0.07-0.04)$ & 0.668 & -0.02 & $(-0.09-0.05)$ & 0.637 \\
\hline Slope difference between $8-42$ weeks minus $0-8$ weeks & 0.19 & $(0.04-0.34)$ & 0.012 & 0.20 & $(0.06-0.34)$ & 0.005 & 0.01 & $(-0.14-0.16)$ & 0.881 \\
\hline \multicolumn{10}{|l|}{ Lifestyle Weight Efficacy ${ }^{\S}$} \\
\hline Slope from Weeks $0-8$ & 0.39 & $(-0.40-1.17)$ & 0.337 & 0.10 & $(-0.57-0.77)$ & 0.773 & -0.29 & $(-0.92-0.35)$ & 0.376 \\
\hline Slope Weeks $8-42$ & 0.13 & $(-0.10-0.35)$ & 0.267 & 0.34 & $(0.02-0.67)$ & 0.040 & 0.21 & $(-0.20-0.63)$ & 0.310 \\
\hline Slope difference between 8- 42 weeks minus 0-8 weeks & -0.26 & $(-1.15-0.63)$ & 0.570 & 0.24 & $(-0.59-1.07)$ & 0.566 & 0.50 & $(-0.39-1.39)$ & 0.269 \\
\hline \multicolumn{10}{|l|}{ Physical Activity - Total MET mins/week } \\
\hline Slope from Weeks $0-8$ & -1.97 & $(-93.97-90.02)$ & 0.966 & 0.06 & $(-78.80-78.91)$ & 0.999 & 2.03 & $(-72.28-76.34)$ & 0.957 \\
\hline Slope Weeks $8-42$ & 1.39 & $(-25.45-28.22)$ & 0.919 & 15.06 & $(-23.74-53.86)$ & 0.447 & 13.67 & $(-35.38-62.73)$ & 0.585 \\
\hline Slope difference between 8- 42 weeks minus $0-8$ weeks & 3.36 & $(-101.13-107.84)$ & 0.950 & 15.01 & $(-82.67-112.68)$ & 0.763 & 11.65 & $(-93.27-116.56)$ & 0.828 \\
\hline \multicolumn{10}{|l|}{ Physical Activity - Walking MET mins/week } \\
\hline Slope from Weeks $0-8$ & -11.16 & $(-44.95-22.62)$ & 0.517 & -2.45 & $(-31.42-26.51)$ & 0.868 & 8.71 & $(-18.67-36.10)$ & 0.533 \\
\hline Slope Weeks $8-42$ & -0.80 & $(-10.65-9.05)$ & 0.873 & -2.67 & $(-16.90-11.56)$ & 0.713 & -1.87 & $(-19.86-16.12)$ & 0.839 \\
\hline Slope difference between 8- 42 weeks minus 0-8 weeks & 10.36 & $(-27.98-48.70)$ & 0.596 & -0.22 & $(-36.08-35.64)$ & 0.990 & -10.58 & $(-49.14-27.98)$ & 0.591 \\
\hline \multicolumn{10}{|l|}{ Moderate Physical Activity MET mins/week } \\
\hline Slope from Weeks 0 - 8 & -10.21 & $(-60.01-39.59)$ & 0.688 & -19.07 & $(-61.78-23.65)$ & 0.382 & -8.85 & $(-49.34-31.64)$ & 0.668 \\
\hline Slope Weeks $8-42$ & 3.21 & $(-11.30-17.71)$ & 0.665 & 17.52 & $(-3.43-38.47)$ & 0.101 & 14.31 & $(-12.17-40.79)$ & 0.289 \\
\hline Slope difference between 8- 42 weeks minus 0-8 weeks & 13.42 & $(-43.06-69.90)$ & 0.641 & 36.58 & $(-16.28-89.45)$ & 0.175 & 23.17 & $(-33.70-80.04)$ & 0.425 \\
\hline \multicolumn{10}{|l|}{ Vigorous Physical Activity MET mins/week } \\
\hline Slope from Weeks $0-8$ & 19.74 & $(-30.78-70.26)$ & 0.444 & 21.07 & $(-22.23-64.37)$ & 0.340 & 1.33 & $(-39.35-42.01)$ & 0.949 \\
\hline Slope Weeks $8-42$ & -0.56 & $(-15.31-14.18)$ & 0.940 & -0.13 & $(-21.45-21.20)$ & 0.991 & 0.44 & $(-26.53-27.41)$ & 0.975 \\
\hline Slope difference between 8- 42 weeks minus $0-8$ weeks & -20.31 & $(-77.72-37.11)$ & 0.488 & -21.20 & $(-74.85-32.45)$ & 0.439 & -0.89 & $(-58.46-56.68)$ & 0.976 \\
\hline
\end{tabular}

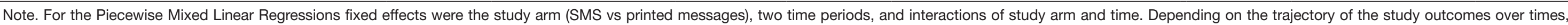

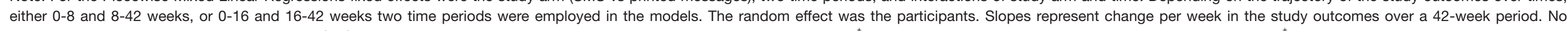

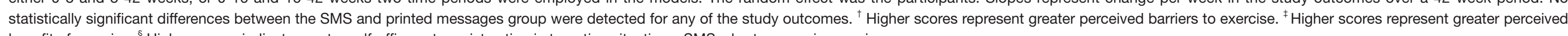
benefit of exercise. ${ }^{\S}$ Higher scores indicate greater self-efficacy to resist eating in tempting situations. SMS, short messaging service. 